\title{
Prospective Teachers' Representations on the Concept of Force
}

\author{
Berta Martini $^{1}$ (D), Marisa Michelini ${ }^{2, *}$, Alberto Stefanel ${ }^{2, *}$ and Monica Tombolato $^{1}$ (D) \\ 1 Dipartimento di Studi Umanistici, University of Urbino Carlo Bo, 60129 Urbino, Italy; \\ berta.martini@uniurb.it (B.M.); monica.tombolato@uniurb.it (M.T.) \\ 2 Physics Education Research Unit, University of Udine, 33100 Udine, Italy \\ * Correspondence: marisa.michelini@uniud.it (M.M.); alberto.stefanel@uniud.it (A.S.)
}

Citation: Martini, B.; Michelini, M.;

Stefanel, A.; Tombolato, M

Prospective Teachers'

Representations on the Concept of

Force. Educ. Sci. 2021, 11, 614.

https://doi.org/10.3390/

educsci11100614

Academic Editors: Federico Corni, Hans U. Fuchs and Angelika Pahl

Received: 1 September 2021

Accepted: 29 September 2021

Published: 7 October 2021

Publisher's Note: MDPI stays neutral with regard to jurisdictional claims in published maps and institutional affiliations.

\begin{abstract}
We present a study on teacher education and, in particular, on Physics. Our assumption is that General Didactics and Disciplinary Didactic constitute two fundamental components of teachers' professional development and therefore both must be used to interpret didactic phenomena adequately. This research involves a sample of 274 prospective teachers, enrolled in the Primary Education Sciences degrees in three Italian Universities (Milano Bicocca, Udine, Urbino,). It concerns the study of the spontaneous representations produced by students to foster understanding of the force concept and on the reasons given to motivate their effectiveness on an educational level and disciplinary one. The research tools and methods were developed by crossing the literature of General Didactics and Physics Education, identifying analytical categories that emerge from two different and complementary perspectives. In the broad spectrum of students' conceptions, given by this double perspective, some aspects stand out: most of the representations do not include the representation of the forces at play, but rather imply a precise didactic approach inherent to the concept of force. This is confirmed by the analysis of the didactic and disciplinary motivations, in which a frequent identification of the two types of motivations emerges.
\end{abstract}

Keywords: prospective primary teachers; representation; concept of force; general didactic and physics education perspectives

\section{Introduction}

\subsection{Background}

In our current society, we are witnessing an educational paradox. On the one hand, the relevance of scientific education to meet the challenges of the 21st century is claimed, but on the other hand, widespread difficulties in the learning of scientific disciplines are detected, as the OECD 2019 report highlights.

This paradox prompts us to question the specific conditions of teaching and learning physics (as a particular scientific discipline) already from the lowest school levels, so that it becomes first and foremost available as a form of knowledge, capable of guiding new generations in a society increasingly influenced by science and technology.

However, such a cultural project requires special attention to Kindergarten and Primary School Teacher Education. Unlike degree courses whose teachings have high epistemic proximity, the study plan of Primary Education Sciences includes a heterogeneity of disciplinary areas.

The challenge is to allow students to gain a high level of competence in a wide variety of specific areas through a limited set of experiences. That suggests identifying synergies between different areas of knowledge through a multi-perspective and integrated education, while attempting to recompose the unity of knowledge beyond disciplinary fragmentation.

The areas involved in this study are General Didactics (understood as the science of teaching) and Physics Education. The aim is to overcome the disciplinary separation between these two areas perceived by prospective teachers and to understand the specific 
contribution that each of the disciplines can provide to the understanding of educational phenomena. Indeed, such areas address the same object from different perspectives. The possibility of integrating these perspectives increases the intelligibility of educational phenomena and contributes, therefore, to the development of teacher professionalism. In detail, these disciplines were involved in the study of spontaneous representations of the concept of force in physics provided by students attending the degree course in Primary Education Sciences. Spontaneous representations are a fruitful object of study since, if properly investigated, they bring out naive conceptions of both teaching contents (inherent to Physics and Physics Education) and children's education (inherent to General Didactics).

The study is placed within a broad theoretical framework that includes theories, constructs, and models from both Physics Education and General Didactics, selected in relation to the specific object of study (naive conceptions of the concept of force), the modes of inquiry adopted (the production of spontaneous representations by prospective teachers) and the purpose of engaging students in an activity of integrating their general and disciplinary teaching knowledge.

The research was conducted as part of the activities of the National Observatory on General and Disciplinary Didactics of the Italian Society for Educational Research (SIRD). The working group, in addition to the Authors of this paper, was composed of Francesca Zanon, Vittorio Del Bianco and Maura Tavano (University of Udine); Rossella D'Ugo (University of Urbino Carlo Bo); Patrizia Magnoler (Pegaso Telematic University); Franca Zuccoli (University of Milano Bicocca).

\subsection{Theoretical Framework from Physics Education Perspective}

The theoretical framework for Physics Education Research is the Model of Educational Reconstruction [1]. It involves the analysis of the structure of the contents, with the disciplinary clarification for a reconstruction for educational purposes, the examination of textbooks and publications, the possible reconstruction of the historical development of ideas, the identification of the main spontaneous ideas of the children, the analysis of the educational significance of every aspect of the chosen topic for design purposes. It involves research on teaching/Learning paths, with the examination of the fundamental nuclei and reasoning, founding the selected topic, the related learning difficulties also in order to develop appropriate teaching materials.

In this perspective, a real theoretical research has concerned the conceptual analysis on the idea of force, which in physics means conceptually retracing the long historical path of the foundation of mechanics, but also the examination of the three main perspectives with which it is faced today: force as interaction, force and motion, strength and balance. They enable different conceptual insights into the field of mechanics. The product of this work, which involved the examination of the approaches of the concept of force on different university texts of different countries and cultures, was the construction of a grid of NF Founding Nuclei (Table A1 in Appendix B). It was one of the backbones of the analysis tool developed with the research.

The subsequent work of identifying the conceptual knots and learning problems of the concept of force involved a research review, which saw the analysis of 118 literature articles, in which the spontaneous and common sense ideas were identified, the learning difficulties with respect to the concept of force at different ages, with investigations of a different nature. The outcome of this work has allowed the construction of a reference catalog, based on literature, for the classification of representations (Table A2 in Appendix C and the related references here quoted). Representations in science teaching is a strand of didactic research in their own right. Visual language has functions and structures similar to those of verbal language [2], is necessary to communicate appropriately and helps to acquire new information. Much work has been carried out in the field of astronomy [3] and several studies point out that representations can be misleading when they are complex, ambiguous and necessarily represent only a specific view, for example, phenomena that take place in three dimensions are represented in a plane [4-7]. This also happens in the study of motions 
and forces. Some authors [8] have suggested that typical representations of astronomic phenomena, such as motions in general, are conceptual models and, as such, can be difficult for students to interpret. There are two reasons: (i) graphic representations require domain-specific knowledge; (ii) graphic representations are often not consistent with the perceptively based models that students have created using their daily experience [8,9]. It therefore seems crucial that teachers help students read the images correctly. To address this issue, we examined the images offered in school textbooks and educational research articles on the different conceptual cores of Table A1 (Appendix B) related to the concept of force.

An original contribution of this research and that flows into its product as a tool of investigation is given by the identification of the representations that support the founding nuclei of the concept of force and identify the conceptual nodes in visual language.

This basis was the reference for the examination of the spontaneous drawings of future teachers with their associated intentionalities.

\subsection{Theoretical Framework from General Didactics Perspective}

As far as General Didactics is concerned, a first issue regards the relationship between General Didactics and Disciplinary Didactics.

In our country, the relationship between General Didactics and Disciplinary Didactics is a debated issue, especially with reference to the needs of both initial and in-service teacher training. In this context, it is unanimously recommended in relation to the need to link "knowing how to teach" not only to a disciplinary competence, but also to a methodological-didactic and didactic-disciplinary competence.

The issue, however, is more controversial than this necessity suggests. Especially, it has long been neglected by general didactic research, which continues to consider as "extraneous" the development of research related to disciplinary didactics and vice versa $[10,11]$. The same happens in other countries. For both major didactic-disciplinary traditions (French and German), the emergence of Disciplinary Didactics is located in the space of teacher education, shared with Educational Sciences.

From this point of view, the relationship between General Didactics and Disciplinary Didactics concerns the possibility of addressing teaching and learning situations from a double perspective: from the top of the general constructs that describe the situation in terms of its macroscopic determinations, or from within the dynamics that teachers and learners activate during the teaching time [12]. In other words, such a relationship allows the teacher to gain a more sympathetic or sharper gaze, respectively, than he or she would be able to direct if he or she were to prescind from such a distinction. In the light of recent research orientations, it is possible to interpret the disciplinary character of didactic competence as indispensable to include knowledge in the study of teaching and learning situations. Placing themselves on the extension of the teaching disciplines, however, disciplinary didactics run the risk of remaining isolated within themselves, to the detriment of the elaboration of didactic discourses (general/disciplinary) that are mutually intelligible. Furthermore, in those countries where only disciplinary didactics exist, a "generalist" tendency emerges to create common spaces for reflection and, in some cases, more unified and convergent frameworks. On the basis of these considerations, from our point of view, it is therefore possible to envisage three directions of research collaboration in the field of disciplinary didactics and between these and general didactics: collaboration in taking responsibility for the content in the understanding of didactic facts; collaboration in identifying the general/specific conditions of didactic facts; collaboration in the work of conceptual reconstruction and modeling of theoretical and practical devices that advance in a critical-normative sense and in an empirical-explicative sense the research on knowledge teaching and learning [13-17].

Among the reference theories for the setting up of the entire work, the theory of Didactic Transposition (TD) was assumed. It allows us to trace the problem of teaching back to the relationship that must be intentionally constructed in the teacher's action 
between savoir savant, savoir à enseigner and savoir enseigné [18]. The savoir savant, in particular, refers to the scientific status of knowledge and can be assimilated to formal knowledge, while the savoir à enseigner and the savoir enseigné refer to the didactic status that knowledge necessarily assumes through teaching. Didactic Transposition thus allows us to resolve a didactic issue of fundamental interest: the relationship between scientific knowledge and taught knowledge. By virtue of this construct, school knowledge is no longer thought of as isomorphic to scientific knowledge. On the contrary, it is endowed with its own specific properties deriving from the process of schooling.

In the subsequent elaboration of the Anthropological Theory of Didactics, Chevallard [13] inscribes the concept of Transposition in the anthropological approach confirming the primacy of an epistemological posture, but provoking an enlargement of the initial theory through the elaboration of tools of analysis and interpretation of transpositional processes.

Among the concepts that can be included in the theoretical framework of TD, that of Didactic Contract is important for the purposes of our work. This concept indicates the set of teacher behaviors that are expected of the student and the student behaviors that are expected of the teacher, related to the knowledge taught [19]. These expectations are tacitly constructed over the course of the school experience in relation to actions or factors that are recognized as typical and are an expression of the meaning attributed by the student to the situation. These expectations and their underlying meaning guide the student's behavior. This construct, which originated in the field of mathematics education, has been used to explain student behavior in many other fields of education where frequent "implicit clauses" were specified. Currently, this construct is found in most General Didactics textbooks intended for teacher education.

Finally, the study of teachers' implicit conceptions of education and learning [20-23] helped direct the analysis of the results, especially with regard to naïve conceptions of teaching and learning. There are many factors that contribute to the development of implicit theories of learning: prior knowledge, personal experiences, the socio-cultural matrix of reference, and the goals one intends to pursue with educational action. The different ways of understanding learning refer both to the constructions elaborated by the scientific community, and to the theories of common sense, shared within the groups and communities of reference [24]. During their training, teachers need to develop an awareness of their implicit theories about education and learning, in order to understand how their personal models can influence educational choices.

A further area of research interest is the use of teaching mediators and in particular the use of images to enhance the understanding of teaching content. The image, in Peirce's triadic conception, is a "sign" conceived as a relationship between three entities: the represented object, the representative sign (the actual image) and the interpreter. In this respect, the didactic choice of images must take into consideration that their effectiveness is not absolute but depends on variables related to the interpreting subject (i.e., the student) and, therefore, also on his or her prior knowledge. For this reason, as argued by Damiano [25], iconic mediators cannot be considered self-sufficient, but must be integrated with other mediators. On the other hand, the contextual use of multiple mediators requires controlling their effects on cognitive load [26] as well as consistency with respect to instructional purposes [27]. In our work, it was also interesting to detect the awareness of teachers in the use of images useful to promote understanding and the ways to integrate different teaching mediators (writing and images) [26]. The use of images as teaching aids involves a number of issues: the different types of images in relation to their communicative function (images to describe, to explain, etc.); the degree of schematization and formalization of images in relation to the progressive process of abstraction and conceptualization of teaching content. The use of [28] figural concepts as conceptualized images is emblematic in this regard: neither pure concepts nor pure images, but functional integration of perceived visual and conceptual qualities. 


\section{Materials and Methods}

\subsection{The Phases of the Research}

The research consists of an exploratory study of the spontaneous representations of the concept of force aimed at a better understanding of it, performed by the students of the undergraduate course in Primary Education. The study was articulated in the following phases.

In a preliminary phase, a table of Founding nuclei and Conceptual Aspects related to the concept of force, according to a didactic-disciplinary perspective (Table A1Appendix B) was constructed; a summary of scientific concepts and common sense ideas related to these concepts was developed by analyzing the literature on learning processes (Table A2-Appendix C); finally, a review of the representations of force in secondary school and university textbooks was carried out.

In the first phase of the research, we formulated the survey protocol aimed at detecting students' spontaneous representations. The protocol asked students to produce 3 different representations of the force that they felt facilitated understanding. The survey protocol had 4 sections. The first section required students to produce a drawing; the second section asked them to describe the proposed representation; the third section asked them to justify the didactic effectiveness of the representation; and finally, the fourth section asked them to justify the disciplinary effectiveness of the representation. Each of the 4 sections was proposed three times to obtain three representations from each respondent (Appendix A)

The protocol was administered to a sample of 274 students of Primary Education Sciences, belonging to different universities (Milan Bicocca, Udine, Urbino), none of whom had followed a university course in Physics or Physics Education.

Next, a grid was developed for a shared analysis of student responses. The grid was articulated in operationalized categories drawn from the relevant literature and a pilot analysis of 30 protocols. Once the pilot analysis was completed, which allowed us to develop the final analysis grid, we proceeded to examine the entire sample of responses (a total of 816 representations and related descriptions and justifications of efficacy). In the last phase of the work, a joint analysis of the results was carried out. The analysis was conducted in two directions: a quantitative analysis based on the calculation of the frequencies of the responses attributable to each category and a qualitative analysis consistent with the theories and constructs of the reference frameworks.

\subsection{The Investigation Tool}

To collect the representations on the concept of force, a pen and paper form was used (shown in Appendix A) structured as follows:

(A) Personal data section

(B) Request section of three "representations that favor the understanding of the concept of force" and, for each of them, a description of the representation and illustration of the didactic and disciplinary motivations on why this representation is effective:

(C) Section of the free "observations and comments".

On a disciplinary level, we expected that a representation of the concept of force concerns a situation in which interactions between physical systems appeared and in which the forces that intervene in these interactions were highlighted, that is the two force vectors each acting on one of the two interacting bodies. The "description" section aims to make explicit and therefore also more intelligible the role of representation and the meaning that the student intended to represent (a type of force, an aspect of the concept of force, a law concerning the concept of force, etc.). We expect coherence between image and description. In the motivation sections, we wanted to collect why the student considers his own representation effective on the didactic level from collect why and on the disciplinary level on the other side (PK and CK in the Shulman PCK perspective $[29,30]$. 


\subsection{Analysis Methods}

To perform the analysis of the representations we set up two rubrics: a first rubric included the disciplinary elements inherent in the concept of force (see Table A1 in Appendix B); the second emerged as a synthesis of literature articles on the conceptual representations of learning on the concept of force (see Table A2 in Appendix C and related references).

The two rubrics were realized as results of two preliminary studies, realized according to the Model of Educational Reconstruction frame and, respectively, related to the elementarization and reconstruction of the force concept for didactic purposes and the analysis of students' learning problems on the topic [1].

The categories of analysis were defined a priori according to the taxonomy stated in rubrics A and B. A redefinition of categories was performed a posteriori including new aspects introduced by students and selecting examples of students' representations and sentences, producing an operational definition of categories. The elementary and often poor nature of the representations has allowed the attribution of a role and a meaning only by integrating the arguments required in the other sections of the investigation tool, in the same way in which the representations of children in conceptual investigations must be integrated with verbalization.

The first three areas of analysis concerned the type of situation represented.

Each representation was included in a mutually exclusive category.

A1-The first area analyzed is that of the typology of proposed situations, which were divided into three categories. A priori we only talked about situations-a posteriori we should distinguish between systems and situations.

A1.1 Common situations/sequence of events-This category includes all the representations made with schematic drawings, realistic or in the form of a vignette or sequence of images, which concern everyday situations, sequences of events, without specific abstract iconic aspects being present, such as vectors, arrows, formulas, graphics, etc., and in which representations of single objects/systems are also grouped (provided that they are not explicitly metaphorical).

A1.2 Concept situations-This category includes three different groups of representations: representations of systems that are not part of everyday life and constitute representative models, such as the solar system or the atom; representations in which iconic elements appear, such as arrows, trajectories, field lines; metaphorical representations or models such as those of a muscular arm or body, of an animal such as the lion.

A1.3 Situations with specific formal symbols-This category includes illustrations in which situations are represented also accompanied by specific formal symbols such as vectors indicating the acting forces, specific formulas, graphics.

The typical common sense representations of the concept of force, summarized in Table A2 (Appendix C) oriented the A2 and A3 analyzes. In fact, we know that a typical idea of common sense is for example that force produces a movement tout court (and not an acceleration), that there are no forces acting on a stationary body (hence the importance of distinguishing between static situations and non-static), which is identified in itself with an action or with a property of the systems and not with a descriptor of the interactions (and therefore always exists as a pair of equal and opposite forces each acting on one of the two interacting systems).

The next aspects concern more specifically how forces are represented and what types of forces were represented, referring to Table A1 of Appendix B, integrated with some aspects that emerged in the students' representations.

A4-The first element of this second level of analysis concerned the number of systems represented, recalling that a force describes an interaction, therefore two interacting systems are expected. Table 1 shows the elements defined a priori (left column) and those introduced a posteriori. 
Table 1. Mutually exclusive categories for the analysis of the system number represented (left column: the categories defined a priori; right column a posteriori categories).

\begin{tabular}{|c|c|}
\hline $\begin{array}{l}\text { A4.1-A single isolated stationary or in motion } \\
\text { system (without any force) } \\
\text { A4.1.1-A single system and a row representing } \\
\text { a force acting on it }\end{array}$ & $\begin{array}{l}\text { A4.4 Compound systems (i.e., systems that } \\
\text { require the use of the rigid body model) }\end{array}$ \\
\hline $\begin{array}{l}\text { A4.2-Two interacting systems, without } \\
\text { representation of forces } \\
\text { A4.2.1-Two systems with only a force acting } \\
\text { only on one of the two }\end{array}$ & $\begin{array}{l}\text { A4.5 Situations involving forces produced by } \\
\text { continuous systems (fluids) }\end{array}$ \\
\hline $\begin{array}{l}\text { A4.3-Two systems in which the representation } \\
\text { of both acting forces is explicit }\end{array}$ & $\begin{array}{l}\text { A4.6 Metaphor (imagine representing a } \\
\text { metaphorical use of of the word force) }\end{array}$ \\
\hline
\end{tabular}

The subsequent levels of analysis concerned aspects that may or may not be present in the representations and therefore non-exclusive categories were constructed.

A5. Types of forces. The types of forces were listed and clustered according to the criteria resumed in Table 2.

Table 2. Type of forces defined a priori and include a posteriori (indentate). The types of forces were clustered in two ways. In the first we recognize three: (A) types of forces defined in physics; (B) types of forces introduced by students; (C) inertial or apparent forces. In the second way, we consider: * active forces; $\Delta$ passive forces; $\bullet$ forces possessed by ... (property of bodies/systems); / / category of forces. The word force is shortened with $\mathrm{f}$.

\begin{tabular}{|c|c|c|c|c|c|c|c|}
\hline Types of Force & (A) & (B) & (C) & * & $\Delta$ & $\bullet$ & // \\
\hline $\begin{array}{l}\text { A5.1 Weight } \mathrm{f} . \\
\text { A5.2 Gravitazional } \mathrm{f} \text {. } \\
\text { A5.3 Elastic } \mathrm{f} \text {. } \\
\text { A5.4 Sliding, volvent, viscous friction } \mathrm{f} \text {. } \\
\text { A5.5 Contact f. (push/pull) } \\
\text { A5.6 Elettric } \mathrm{f} \text {. } \\
\text { A5.7 Magnetic } \mathrm{f} \text {. } \\
\text { A5.8 Nuclear } \mathrm{f} . \\
\text { A5.9 Archimede/hydrostatic } \mathrm{f} \text {. } \\
\text { A5.10 Centrifugal } \mathrm{f} \text {. } \\
\text { 5.11 Centripetal } \mathrm{f} \text {. } \\
\text { A5.12 Apparent/fictitious/inertial f. } \\
\text { A5.13 Muscular/physical f.-physical effort. } \\
\text { A5.14 F. possessed by an object/system/entity }\end{array}$ & $\begin{array}{l}\text { (A) } \\
\text { (A) } \\
(\mathrm{A}) \\
(\mathrm{A}) \\
(\mathrm{A}) \\
(\mathrm{A}) \\
(\mathrm{A}) \\
(\mathrm{A}) \\
\text { (A) }\end{array}$ & $\begin{array}{l}\text { (B) } \\
\text { (B) } \\
\text { (B) }\end{array}$ & $\begin{array}{l}\text { (C) } \\
\text { (C) }\end{array}$ & $\begin{array}{l}* \\
* \\
* \\
* \\
* \\
* \\
*\end{array}$ & $\begin{array}{l}\Delta \\
\Delta\end{array}$ & $\begin{array}{l}\bullet \\
\bullet \\
\bullet \\
\bullet\end{array}$ & $\begin{array}{l}1 / \\
1 / \\
1 /\end{array}$ \\
\hline
\end{tabular}

A6. Effects of a force. When the representation concerns the (explicit) presence of force effects identified a priori in "acceleration" and "deformation" and integrated a posteriori with "movement/displacement" and "other effects" (such as attraction, which instead of as a characteristic force for some students is an effect that identifies some forces).

A7. Presence of free or applied vectors/arrows. The images including these elements were distinguished considering:

- applied vectors representing forces (vectors whose point of application is on one of the systems represented and in which there are clear indications that the arrow actually represents a force and not simply a displacement)

- free vectors (vectors that explicitly represent forces, but which do not have a point of application on a system; vectors which appear more to represent a force field than a force acting on a system, such as the gravitational field)

- $\quad$ arrows (arrows that do not indicate forces, but more often displacements, trajectories).

- Arrows that connect two images that represent different phases of the same situation, that is representing a temporal hierarchy, have not been included in any of the indicated categories. 
A8. Point of application. For the applied vectors only, the representations were distinguished in which: the point of application is the center of mass; the forces are applied in a generic point.

A9. Apart from that, the representations in which the free body diagram is present as a separate representation from that of the illustrated physical situation have also been indicated.

Finally, the presence of the following aspects was counted: A10-Composition of forces; A11-Force and momentum relationship; A12-Moments of forces; A13-Force measurement; A14 - the presence of formulas; A15—the presence of graphics.

A posteriori, we counted, also, in which other physical quantities explicitly emerge in addition to force (A 16-Link of the concept of force with other quantities), such as: A16.1 Energy/Work; A16.2 Power; A16. 3 Magnetic field.

The categorization of pedagogical and disciplinary motivations was rather difficult, as students more often brought motivations that include both didactic and disciplinary aspects, rather than reversing the motivations.

As regards the disciplinary motivations (or purposes), the following dimensions were identified:

B1-Ontological-existential aspects

B2-Identification of specific aspects/elements of the force

B3-Understanding of specific aspects (the representation is aimed at...)

B4-Introduction of a specific type of force

B5-Role of formalization

Finally, the following analysis criteria were identified in relation to the didactic motivation included among the disciplinary motivation:

$\mathrm{BC} 1$. activate specific didactic processes connected to the concept of force (e.g., the role of the presence of formal aspects in the representation, rather than visualizing or contextualizing the concept of force)

BC2. Role of everyday life to: (A) evoke a situation known to children in which there was a force; (B) let children live/experience; (C) explain a concept; (D) make people understand/understand.

BC3. general didactic motivations (contextualize physical concepts in everyday life [there is no reference to the concept of force]; activate active teaching; stimulate reflection; promote transversal activity, as physical/motion education

Out of context, all the representations of metaphorical images (the lion, the father, the fortress) were indicated, which did not imply any aspect of the concept of force in physics.

Considering the didactic motivations, here, the categories are defined:

C1. Evocative. We included in this category responses that evoke everyday life experiences by distinguishing the subject of the experience:

C1.1. Experiences of the student or others (thus not the child) that can be traced to a sociocultural universe, including those from the media

C1.2. Experiences lived and/or observed by the child.

C2. Justification related to intention to act didactically

C3. Formal-constructed justification. We included in this category student responses that made clear reference to the correct formal representation (graphic or symbolic)

C4. Justification by Formal Proxy. We included in this category the students' answers in which explicit reference was made to the clauses of the didactic contract

C5. Justification related to comprehensibility. We included in this category the students' responses that made explicit reference to the simplicity of the representation, its intuitiveness, clarity, immediacy, appropriateness with respect to the age of the student, etc.

C6. Metaphorical-affective justification. We included in this category the responses of students who made explicit reference to affective and emotional aspects or who used metaphorical representations. 


\subsection{The Context of the Research and the Sample}

The images were collected in the courses of Primary Formation Science degrees of three different Italian Universities, in the academic year 2019/20: at the University of Milan Bicocca in the course of Image Education; at the University of Udine in the course of Physics Education; at the University of Urbino in the course of General Didactics. In each of the three contexts, the images were collected before the students had addressed the concept of force, but after they received a formation on General Didactics. Therefore, the analysis of the images allows the monitoring of conceptual representations gained in common experience and in upper secondary school education. It highlights also the autonomy in transposing PK, acquired in the general didactics course, in PCK, or the students' formative needs related to this competence.

The analysis was carried out on the illustrations of: $N=274$ students of Primary Education, which produced a total of $n=816$ representations (In Milan: $N_{\text {MIB }}=102$ students of the first years producing $n_{M I B}=306$ representations; in Udine $N_{U D}=95$ students of the third year producing $n_{U D}=283$ representations; in Urbino $N_{U R}=77$ students of the first year producing $\mathrm{n}_{\mathrm{UR}}=227$ representations ( 5 students, 2 from Udine and 3 from Urbino, produced 2 images instead of the 3 requested) (see Table 3 ).

Table 3. Numbers of images and students of our samples divided for the three universities involved.

\begin{tabular}{ccc}
\hline University & Images & Students \\
\hline MIB & $\mathrm{n}_{\mathrm{MIB}}=306$ & $\mathrm{~N}_{\mathrm{MBI}}=102$ \\
UD & $\mathrm{n}_{\mathrm{UD}}=283$ & $\mathrm{~N}_{\mathrm{UD}}=95$ \\
UR & $\mathrm{n}_{\mathrm{UR}}=227$ & $\mathrm{~N}_{\mathrm{UR}}=77$ \\
\hline TOT & $\mathrm{n}=816$ & $\mathrm{~N}=274$ \\
\hline
\end{tabular}

To highlight the few differences in the results obtained in the three contexts and instead highlight the generality of most of them, we report data both for each university and for the full sample.

\section{Results}

In this section, we present some of the more relevant results of the data analysis.

\subsection{Typology of Situations Represented}

Table 4 and Figure 1 summarize the data concerning the situations represented. The most frequent representations concern common situations (prevalently) or sequences of events ( $2 \%$ ): devoid of any formal entity (256 equal to $32 \%$ ) or with abstract iconic elements, such as arrows, trajectories, field lines, but in which they are not explicitly or obviously represented force vectors (242 equal to $30 \%$ ). Representations in which specific formal elements can be identified are just under $1 / 3$ of the total representations (230 equal to $28 \%$ ). See Figure 2 for examples.

Table 4. Numbers of images and students of our samples divided for the three universities involved.

\begin{tabular}{ccccccc}
\hline & A1.1 & \multicolumn{2}{c}{ A1.2 Concept Situations } & A1.3 \\
\hline University & $\begin{array}{c}\text { Common } \\
\text { Situation/Events } \\
\text { Sequences }\end{array}$ & $\begin{array}{c}\text { (a) Model } \\
\text { System (i.e., } \\
\text { Solar System) }\end{array}$ & $\begin{array}{c}\text { (b) Common Situation } \\
\text { with Abstract Iconic } \\
\text { Elements (i.e., Arrows, } \\
\text { Formula) }\end{array}$ & $\begin{array}{c}\text { (c) Metaphor } \\
\text { System }\end{array}$ & $\begin{array}{c}\text { Situation with } \\
\text { Specific Formal } \\
\text { Symbols (Forces } \\
\text { Vectors) }\end{array}$ \\
\hline MIB & 82 & 8 & 72 & 42 & 122 & 118 \\
UD & 88 & 8 & 107 & 2 & 92 \\
UR & 85 & 2 & 63 & 72 & 332 \\
\hline TOT & 255 & 18 & 242 & 28 & 45 \\
\hline
\end{tabular}




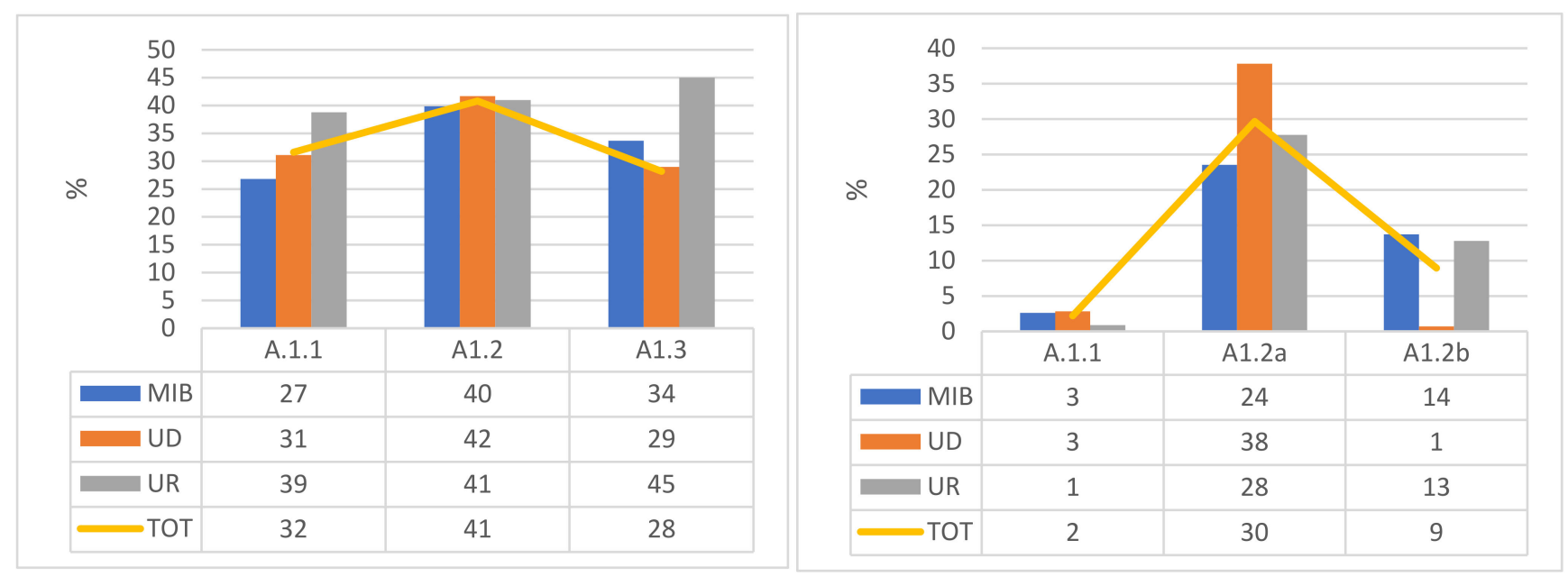

Figure 1. Frequencies categories of situations (see Table 3) represented. On the right, the detail of the distribution on the three areas included in the category A1.2.
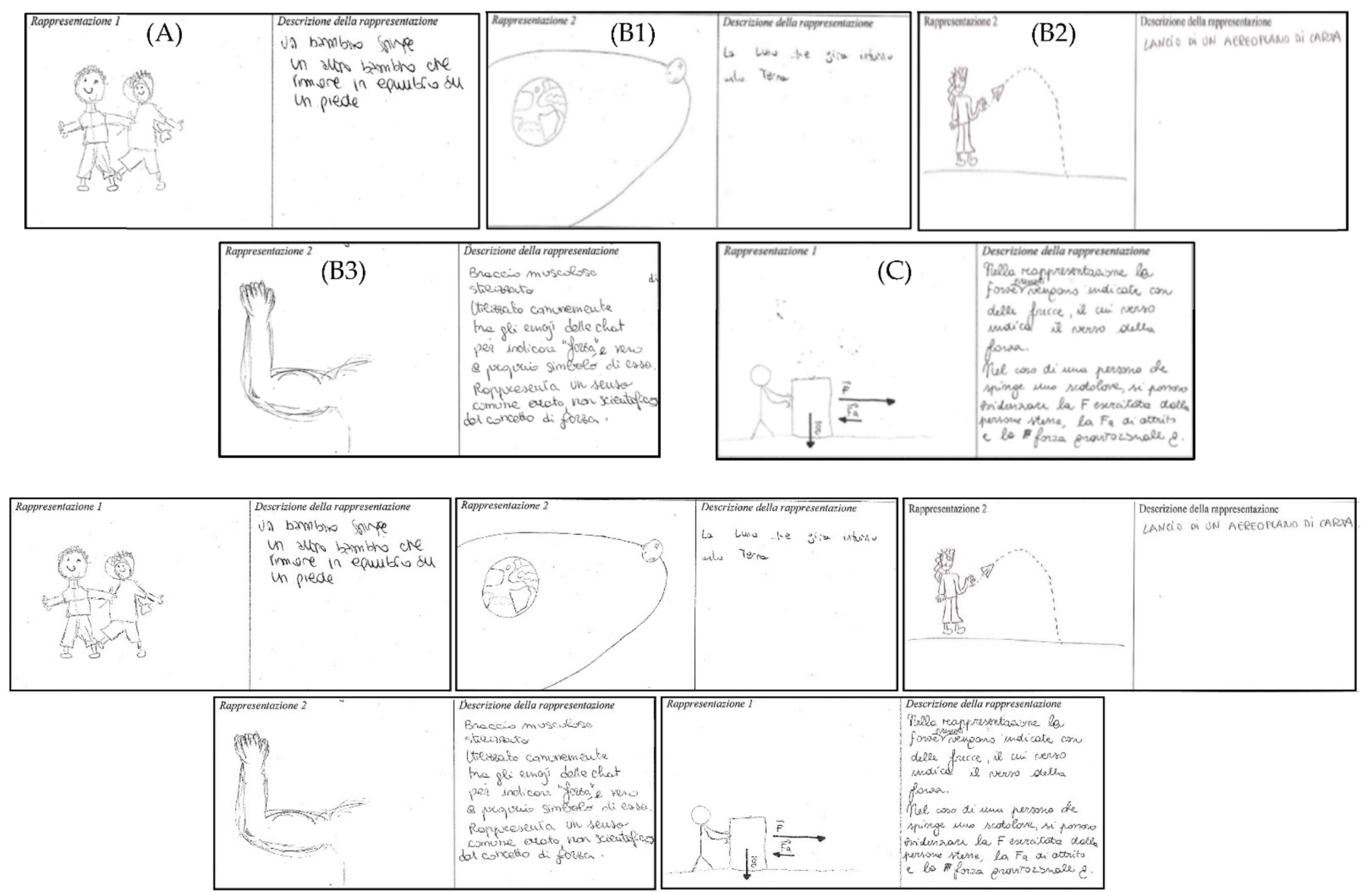

Figure 2. Examples of situation represented: (A) Common situation; (B1) Model representation (solar system in this case); (B2) Common situation with abstract iconic element (the trajectory in the picture); (B3) metaphoric representation (the muscular arm in this case); (C) situation with specific formal symbols (vectors representing the force acting on the box in the picture).

The representations of systems that metaphorically recall the word force (muscular bodies, a barbell, an animal or a person inspiring force) are less than $10 \%$ (72-Figure 1). These types of representations are almost absent in the Udine sample $(1 \%<)$. While these are more significantly present in the Milan and Urbino samples $(14 \%$ and $13 \%$ of the 
representations, respectively), where the data collection was performed in other courses than Physics Education one.

Model situations (such as the solar system) are present in less than 3\% of Udine and Milan samples and are almost absent in Urbino. These percentages would rise to 3\%, 5\%, $1 \%$ if we also included the representations of gravitational interactions with a view outside the Earth in which the acting forces are represented and which therefore were included in category 1.3 .

Overall, in eight cases formulas were included (the most frequent is $\mathrm{P}=\mathrm{mg}$ ), in only one case there are graphs, three are the concept maps (all in the Udine sample).

$494(61 \%)$ representations involve non-static situations, 247 (30\%) ones represent static situations. The remaining $9 \%$ are not situations, but for instance a formula, a conceptual map, a person or system with explicit metaphorical/allegorical meaning.

The majority of non-static situations represented is an indicator that many students of our sample (at least $\frac{1}{4}$ ) believe that it is necessary to highlight the presence of a force with the effects it produces, movement or displacement according to the motivation given by these students. The presence in many representations of arrows, trajectories or other abstract iconic elements is another indicator of analogue belief. Some students underlined in the written comments the difficulty of the need to represent situations of motion to highlight the presence of a force.

On the other hand, some students (about 10\%) also explicitly provided for static situations alongside situations in which systems in motion were represented. These students show an awareness at least of the main learning problems of students with regard to strength and movement.

353 images, or $43 \%$ (418 images or $51 \%$ if metaphorical images are also included) include a person. Over $1 / 3$ concerns games or sports situations, with the explicit didactic intent of involving physical/Motion/sport education as well.

Tug of war (12\%-44/353, see Figure 3) 44 -the winning team is the one "using greater force") is a game quite present in the representations in which some of the acting forces are also often inserted. This context is evoked both to represent situations of equilibrium (equal forces) and disequilibrium situations (win the team that "makes more strength" on the rope). The equality of the forces acting on each of the ends of the rope never emerges.

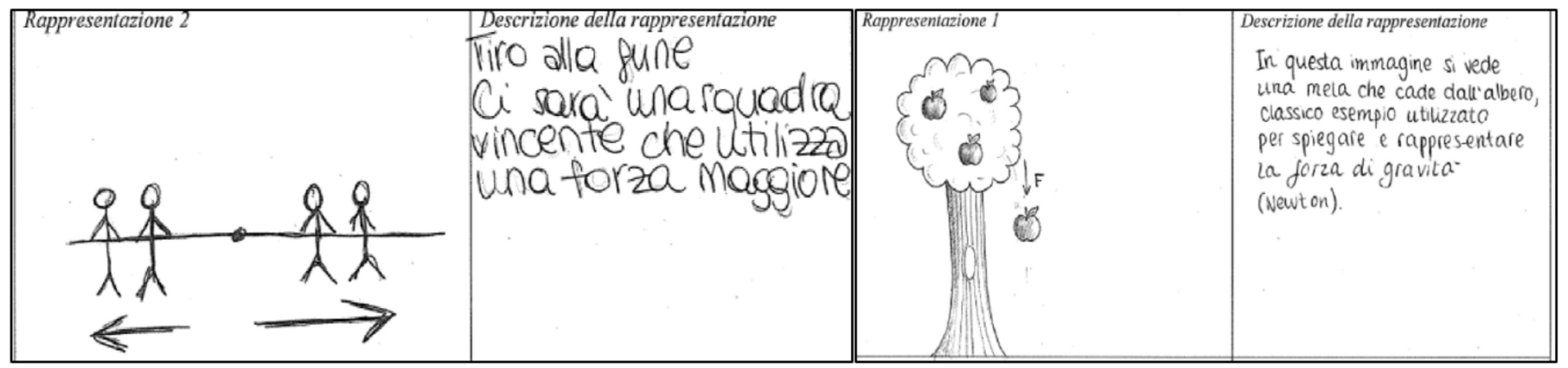

Figure 3. Examples of tug of war and falling apple representations.

Another frequent context represented is that of falling objects $(112 / 813-14 \%$ see Figure 3), of which $2 / 3$ illustrate apples falling from the tree, recalling explicitly the fable of Newton's apple. In $1 / 3$ of cases, the falling object is left by a hand or a person. representations which, on the one hand, reveal the need to represent a realistic context, but which also can hide or enhance the unsolved distinction between the acting cause and the efficient cause of why "the apple has fallen".

Often the system under attention is not identified and the interactions involved in the representations are never identified in an explicit way.

The same context is used to evoke different forces. For instance, a person launching an object (43/353-12\%, i.e., a ball, a vortex, a weight) can be represented both to "illus- 
trate/explain" "the force of gravity", and to "introduce" "the force of the launch" or the intensity of that force according to the distance reached by the launched object.

In other cases, it is the context or the specific action taken that comes into play and that determines the criteria of distinction, such as when considering the different directions of a force.

\subsection{Number of Systems Represented}

Figure 4 and Table 5 summarize the analysis of the number of systems represented. Over half of the representations involve two systems (53\%). In most cases, the force is described in words and represented in the drawings as situations of action of one body on another (action of the Earth on a body; action of the hand on a ball).

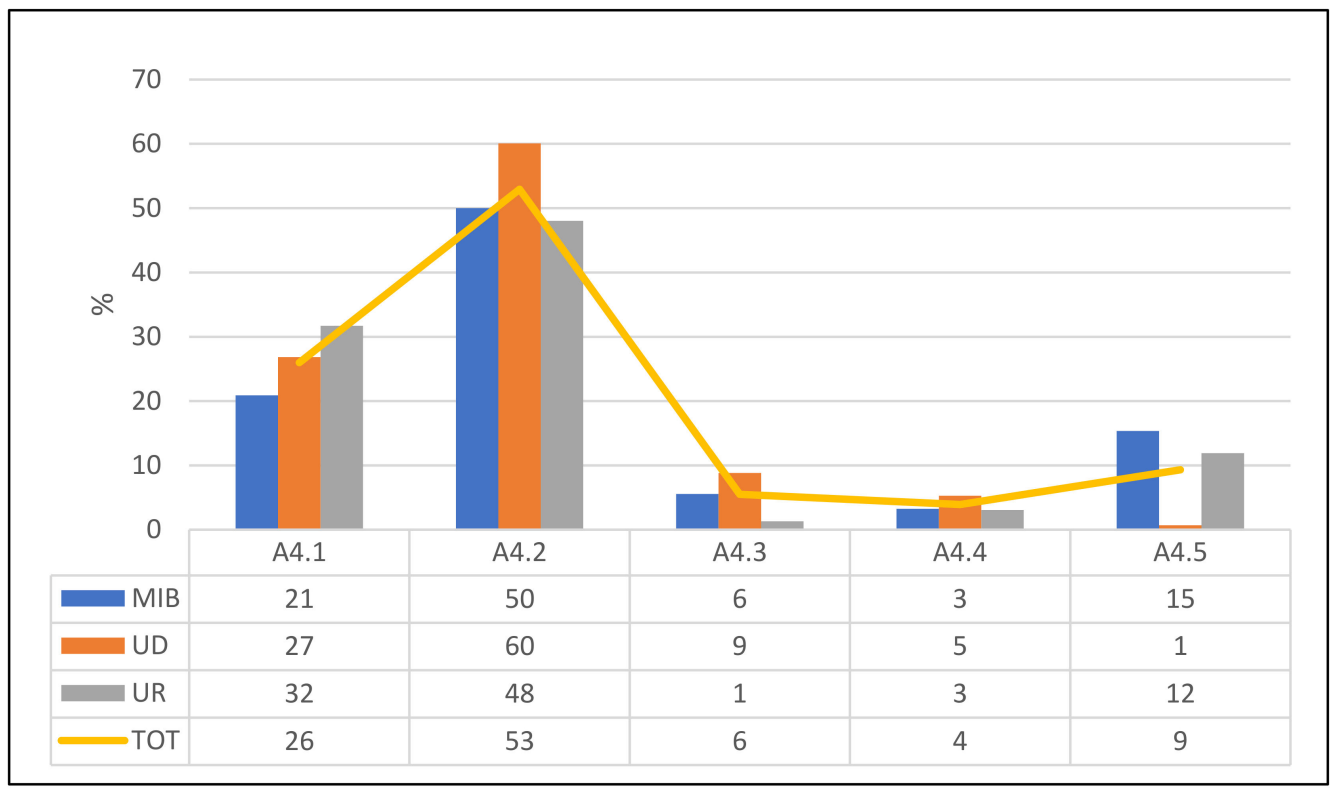

Figure 4. Distribution of the categories related to the number of systems represented (see Table 3 for an explicit definition of the categories).

Table 5. Numbers of systems categories represented: absolute frequencies and percentage specified per sample and for each of the three contexts.

\begin{tabular}{|c|c|c|c|c|c|c|c|c|}
\hline \multirow{2}{*}{ Category } & \multicolumn{2}{|c|}{ MIB } & \multicolumn{2}{|c|}{ UD } & \multicolumn{2}{|c|}{ UR } & \multicolumn{2}{|c|}{ Tot } \\
\hline & $\mathbf{N}$ & $\%$ & $\mathbf{N}$ & $\%$ & $\mathbf{N}$ & $\%$ & $\mathbf{N}$ & $\%$ \\
\hline A4.1-A single isolated system & 47 & 15 & 49 & 17 & 63 & 28 & 159 & 26 \\
\hline A4.1.1 —A single isolated system and one or more forces & 17 & 6 & 27 & 10 & 9 & 4 & 53 & 6 \\
\hline A4.2-Two interacting systems & 153 & 52 & 170 & 61 & 109 & 47 & 422 & 53 \\
\hline A4.2.1-Two interacting systems (without force) & 108 & 38 & 129 & 46 & 87 & 38 & 324 & 40 \\
\hline A4.2.2-Two interacting systems and a force & 32 & 10 & 27 & 10 & 10 & 4 & 69 & 8 \\
\hline A4.2.3 - Two interacting systems and two forces & 13 & 4 & 14 & 5 & 12 & 5 & 39 & 5 \\
\hline A4.3 Compound systems (rigid body) & 17 & 6 & 25 & 9 & 3 & 1 & 45 & 6 \\
\hline A4.4 continuous systema (fluids) & 10 & 3 & 15 & 5 & 7 & 3 & 32 & 4 \\
\hline A4.5 Metaphoric representation & 47 & 15 & 2 & 1 & 27 & 12 & 76 & 9 \\
\hline
\end{tabular}

The reciprocity of the interactions is represented only in $5 \%$ of the cases in which the situation is illustrated with two acting forces, moreover in many cases with different intensities. The contexts in which the interaction between two systems with two forces is typically represented are: the interactions between magnets; the tug of war; the Earth/system interaction. 
The forces of interaction are never represented, in all situations where bodies in contact are represented.

In a large majority, the forces involved in the representation are constant and continuous forces and only $10 \%$ are impulsive forces.

\subsection{Types of Force}

The diagram of Figure 5 and circle diagrams of Figure 6 synthesized the results of the analysis of types of forces.

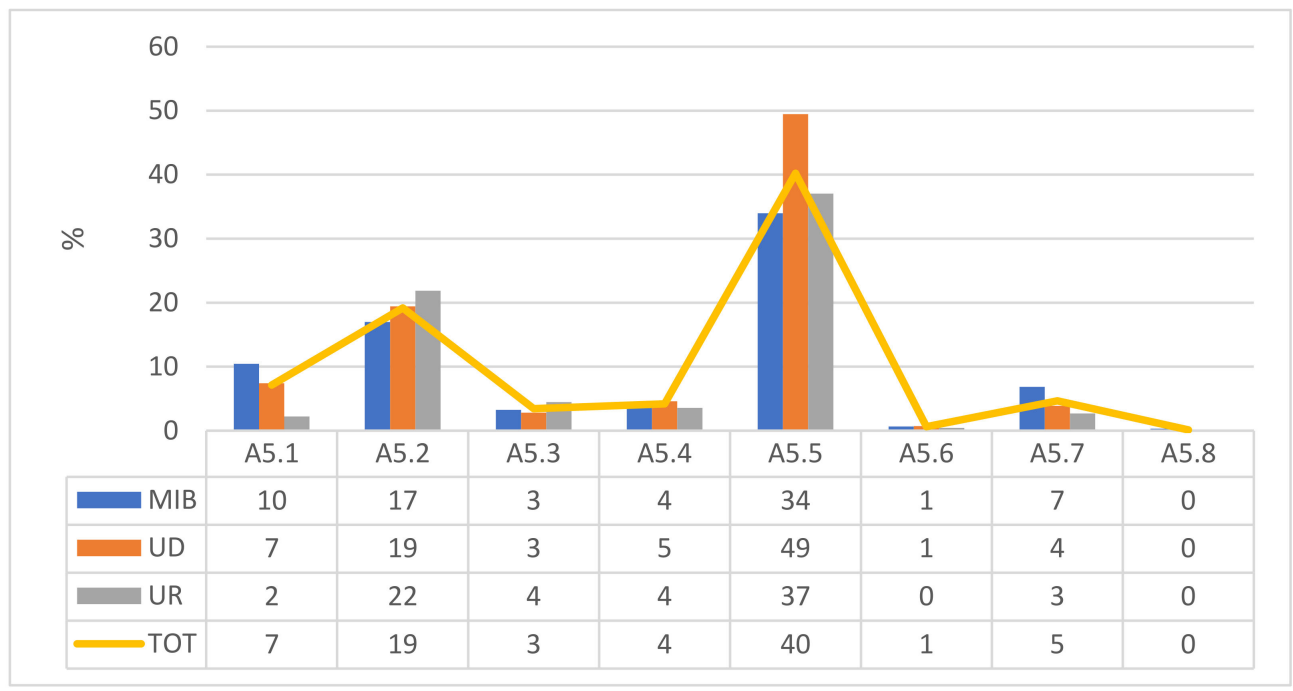

Figure 5. Distribution of the categories related to the physics forces.
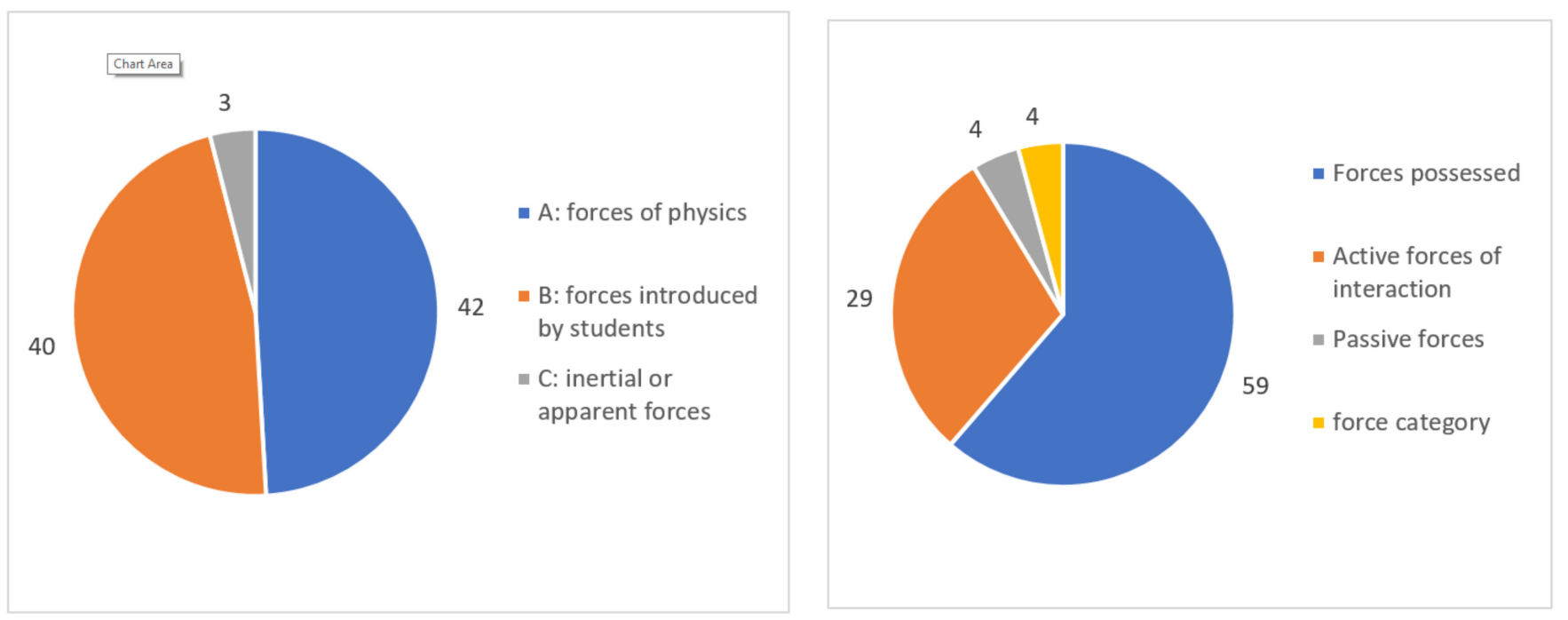

Figure 6. Circle diagrams of the two different clusters of forces.

Among the types of forces represented, those in contact prevail (about half of the representations), followed in order by the "force of gravity" and "weight force" (mentioned in almost all cases in a distinct/alternative way and in three cases cited jointly), friction forces, magnetic forces, elastic forces. The forces introduced by students and those emerging from physics are present with almost equal weight. The concept of force as a property possessed by a body is also very relevant.

It is interesting, for the purposes of this work, to deepen how the Force of Gravity and the weight force are cited in the representations (see Figure 7 for examples as well as images in Figures 2 and 3). The force of gravity is mentioned in 157 cases, 155 of which are 
adequately mentioned. Weight force is mentioned in 59 cases in total, but only in 44 is it adequately presented. As we can see, the force of gravity is mentioned almost three times more frequently than the weight force. In this regard, we observe that the word weight has not been classified as weight force, when used to indicate an object (i.e., an object on a balance).
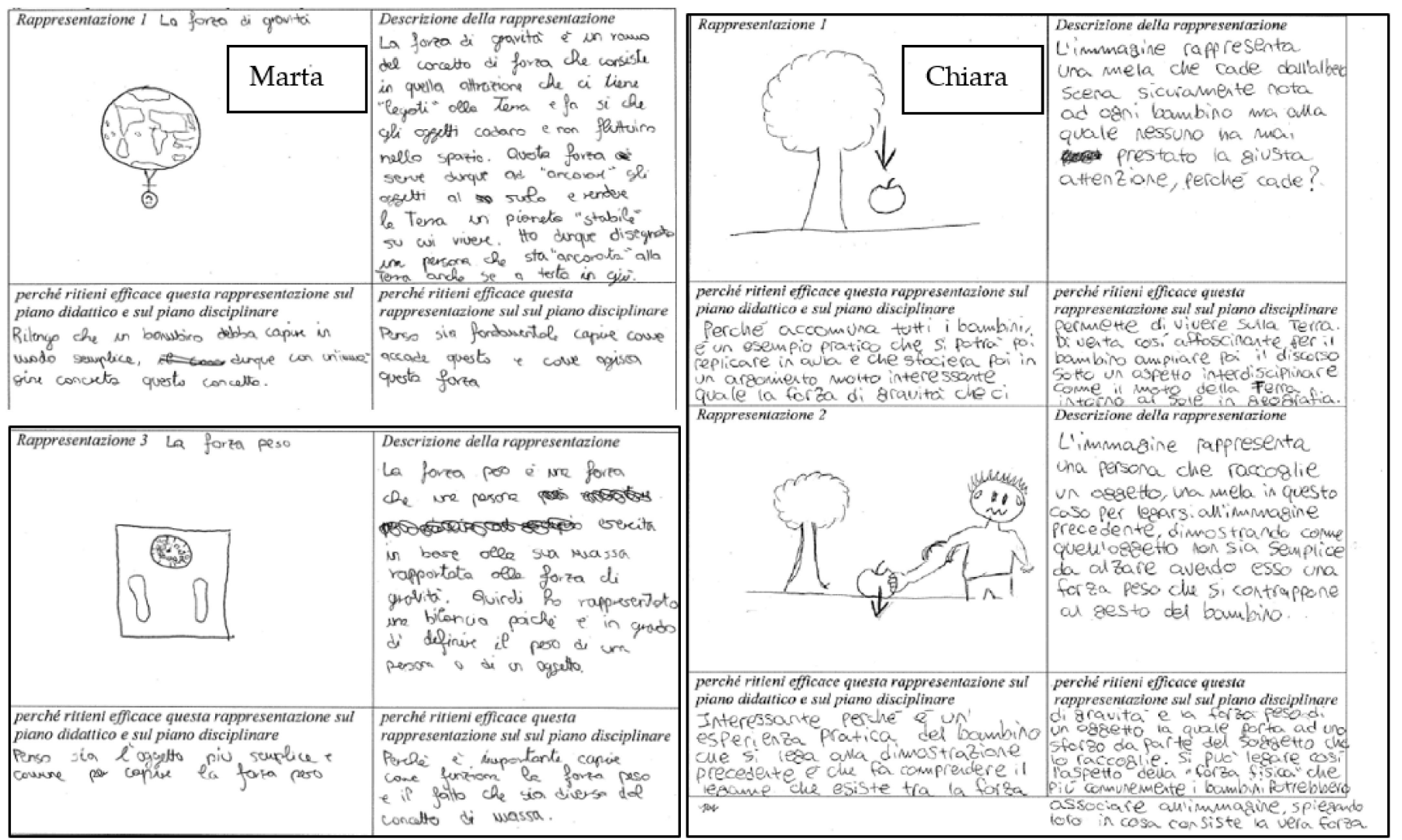

Figure 7. Examples of representation involving the gravitational force.

The force of gravity is almost always identified with an attractive force or action of a massive body (the Earth, the Sun) (although it is sometimes generically referred to as gravity), or associated with the fall of a grave (more often an apple). Weight is a property possessed by a body (17 cases versus 2 of the "force of gravity"). the weight "produces" or "exerts" a force (2 cases), or is a "force daily and without noticing exerted on the earth", or identified tout court with the acceleration of gravity.

Only in nine cases are weight force and gravity mentioned jointly of which only in three cases are weight force and the gravity force identified; in the other cases, the weight force is connected to gravity in an unspecified way: "children can investigate the force weight, linking it to gravity", "the weight force is a force that a person exerts based on his mass in relation to the force of gravity".

It is interesting to observe that some students representing some situations, such as the solar system, the earth-moon system, astronaut, person standing on the surface of the Earth, falling objects (more often apples) stress the presence of the gravitational force. Representing other situations (force acting on a body resting on a horizontal or inclined plane), the same student cited the weight force.

\subsection{Effects of a Force}

One part of the representations concerns the effects that a force acting on a system has on them. Table 6 shows the frequencies with which the students of our sample cited the different effects of a force. 
Table 6. Frequencies of the effect of force cited by the student.

\begin{tabular}{ccccc}
\hline $\begin{array}{c}\text { \% } \\
(\mathbf{N}=\mathbf{3 2 1})\end{array}$ & $\begin{array}{c}\text { A6.1 } \\
\text { Deformation }\end{array}$ & $\begin{array}{c}\text { A6.2 } \\
\text { Acceleration }\end{array}$ & $\begin{array}{c}\text { A6.3 Displacement } \\
\text { Movement }\end{array}$ & $\begin{array}{c}\text { A6.4 } \\
\text { Other Effects }\end{array}$ \\
\hline MIB & 2 & 2 & 10 & 2 \\
UD & 6 & 2 & 53 & 7 \\
UR & 1 & 2 & 12 & 1 \\
\hline TOT & 10 & 5 & 75 & 10 \\
\hline
\end{tabular}

$321 / 813$ representations ( $39 \%$ of the entire sample), of which $51 / 306$ representations of MIB, 219/283 representations of UD, 51/224 of UR, explicitly involved the effects of a force. These representations were made by 168 students ( $61 \%$ of the total sample), of which 97 were from Udine, 29 from Milano Bicocca, 42 from Urbino.

The more frequent effect of a force is a displacement or a movement, for the majority of these students ( $75 \%$ of the total of the 321 representations, in which the Udine sample has more than double the weight of the other two samples).

Only in a few cases the only effect of the force acting on an object is a deformation $(10 \%)$ or an acceleration $(5 \%)$ of the object itself.

The following sentences of the students highlight the different perspectives with which the connection between force and movement is formulated:

- " "a moving object can exert its own force"

- "example in which forces in a certain sense cause a movement of bodies"

- " "in physics to move or push an object a force is applied"

- " "to produce a displacement you need a force"

- "the representation [a person lifting an object] allows us to understand that force concerns the displacement and mass of objects. Applying a force therefore implies the displacement of an object that has a certain mass "

- $\quad$ "Highlights that an object that was previously a rest moves as a result of the action of a subject

These different perspectives are also known in the literature (see Table A2 in Appendix C) as learning nodes. However, the analysis of our representations suggests that situations in which a stationary body is put in motion must be treated separately.

\subsection{Vectors and Forces}

As is well known, a force is characterized by its nature as an applied vector. We should therefore expect a large presence of these formal entities in the representations. As can be seen from Table 7 though.

Table 7. Frequencies of the formal iconic elements included in the representations.

\begin{tabular}{cccc}
\hline$\% \mathbf{~ ( N ~ = ~ 3 9 4 ) ~}$ & A7.1 Applied Vectors & A7.2-Free Vectors & A7.3-Arrows \\
\hline MIB & 9 & 15 & 13 \\
UD & 7 & 14 & 22 \\
UR & 4 & 7 & 9 \\
\hline TOT & 20 & 36 & 44 \\
\hline
\end{tabular}

$394 / 813$ representations ( $48 \%$ of the total), of which $149 / 306$ by MIB, $168 / 283$ by UD, $77 / 224$ by UR, include formal iconic elements, of which: applied vectors ( $20 \%)$; free vectors (36\%); arrows (44\%).

The vectors are applied to the center of mass in less than half of the cases. In the remaining part of the cases, they are applied to other points of the body (typically the contact points). Only in 12 representations (less than 3\%) appears the free body diagram. This diagram is separated by the situation image only in $1 \%$ of cases. 
Free vectors are mostly used to represent vector fields (e.g., the gravitational field around the Earth), or to represent the direction, direction and intensity of the applied force separately from the representation of the situation (See the examples in Figure 3).

Arrows that do not have an explicitly evident role as force vectors were classified as arrows and mostly illustrate the displacements of systems.

Direction towards: rather than introducing the concept of force as a vector, the purpose of the representations is to show that some forces act horizontally, others vertically, some attract others repel, you can pull an object, but you can also push it. In other words, a unified concept of force is not created, but rather a collection of figurines in which the contingent aspects determine the significance of the examples, rather than proposing them as examples to construct the different elements that contribute to forming the concept of force.

\subsection{Other Aspects}

The other aspects included in the students' representations appear in very few cases as resumed in Table 8.

Table 8. Frequencies of occurrence of other aspects.

\begin{tabular}{ccccccc}
\hline$\% \mathbf{~ ( N ~ = ~ 8 1 3 ) ~}$ & $\begin{array}{c}\text { A9-Forces } \\
\text { Composition }\end{array}$ & $\begin{array}{c}\text { A10-Connection } \\
\text { Force -Momentum }\end{array}$ & $\begin{array}{c}\text { A11-Moment } \\
\text { of a Force }\end{array}$ & $\begin{array}{c}\text { A12-Measure } \\
\text { of a Force }\end{array}$ & $\begin{array}{c}\text { A13- Formulas } \\
\text { A14. Graphs }\end{array}$ \\
\hline MIB & 8 & 0 & 0 & 1 & 1 & 0 \\
UD & 11 & 0 & 0 & 5 & 2 & 1 \\
UR & 2 & 0 & 0 & 0 & 2.1 & 1.5 \\
\hline TOT & 7.3 & 0 & 0.2 & 0.4 \\
\hline
\end{tabular}

Here we can observe that only a minority of students (7\%) included in his representation the composition of forces, a very important aspect characterizing the nature of a force. More frequently the composition regards the sum of collinear forces. It highlights a great need of the students concerning this aspect.

The aspects of Table A1 totally absent from the representations are: the nuclear forces (except for a single representation in which an atom is represented); the force-momentum relationship; the moment of a force (with the exception of a representation in which there is the concept of the moment, but expressed as force and arm.

Instead, references appear to other quantities connected to the concept of force, as reported in Table 9, where energy is the quantity more often associated with a force or more frequently identified with it.

Table 9. Frequencies of quotation of other quantities related to the concept of force in the students conceptions.

\begin{tabular}{cccc}
\hline & A15.1 Energy/Work & A15.2 Power & A15. 3 Magnetic Field \\
\hline MIB & 4 & 4 & 1 \\
UD & 9 & 0 & 0 \\
UR & 3 & 3 & 0 \\
\hline TOT & 16 & 7 & 1 \\
\hline
\end{tabular}

\subsection{Disciplinary Motivation}

As discussed in the method section, the disciplinary effectiveness highlighted by students was grouped in five areas.

The first area concerns ontological/existential aspects. Table 10 shows the aspects that emerged and the frequency of occurrence. 
Table 10. Frequencies of quotation of other quantities related to the concept of force in the students' conceptions.

\begin{tabular}{lcccc}
\hline \multicolumn{1}{c}{ Category } & MIB (n) & UD(n) & UR (n) & TOT (n) \\
\hline Force as interaction & 4 & 3 & 7 & 17 \\
Force as action (of a body on another one) & 11 & 11 & 9 & 31 \\
Force as transmission of something & & 4 & 2 & 6 \\
Connection force-movement & 13 & 53 & 22 & 88 \\
To put in motion a body is needed a force & 1 & 6 & 8 & 15 \\
Connection force acceleration & 5 & 6 & 3 & 14 \\
Recognition of the existence of a forca & 3 & 25 & 3 & 31 \\
Recognition of the application of a force & 1 & 1 & 5 & 7 \\
\hline
\end{tabular}

Less than $5 \%$ of students explicitly propose his representation to illustrate the nature of a force. It is identified only in 17 cases as an interaction. More often (31 versus 17) force is identified as the action of one system on another (thus not recognizing reciprocity). This agrees with the proposed representations, in which either only one system or the action of one system on another is represented and not the reaction of the latter on the first.

The idea of force as transmission is also present (6 representations), although it is never clear which entity is being transmitted.

The connection force-movement emerged in $13 \%$ of representations.

Concerning specific aspects/elements of force, Table 11 shows the aspects that emerged and the relative frequencies.

Table 11. Specific aspects concerning force emerged in the disciplinary motivation of students.

\begin{tabular}{cccccc}
\hline Sut & MIB & UD & UR & TOT & \% TOT \\
\hline Aspects correlated to the vectorial nature of force & 7 & 57 & 3 & 67 & 8 \\
\hline Intensity & 9 & 48 & 22 & 79 & 10 \\
Direction & 7 & 18 & 3 & 28 & 4 \\
Versus & 2 & 7 & 5 & 14 & 2 \\
\hline Composition-Sum of forces & 10 & 19 & 12 & 61 & 8 \\
\hline Equilibrium & 12 & 11 & 10 & 33 & 4 \\
Disequilibrium & 17 & 88 & 16 & 121 & 15 \\
\hline Effects of forces & & & & & 15 \\
Displacement/movement & 17 & 88 & 16 & 121 & 12 \\
\hline Effect of a force as an evaluation & 1 & 7 & 4 & 12 & 2 \\
\hline of its intensity & 11 & 19 & 13 & 43 & 6 \\
\hline Property of force (Attraction/repulsion) & 1 & 0 & 2 & 3 & \\
\hline Comprehension that to an action correspond & & & & \\
a reaction & 3 & 8 & 2 & 13 & \\
\hline Coexistence of multiple forces & 2 & 3 & 1 & 6 & \\
\hline Distinction weight-mass & 1 & & 3 & 4 & \\
\hline Existence of attractive and repulsive forces & 27 & 157 & 25 & 209 & 26 \\
\hline Role of mass in the force & & &
\end{tabular}

In 513 cases (63\%) the motivation given by the students is linked to the fact that the representation illustrates or allows the introduction of a specific type of force (in some cases even more than one). Figure 8 shows the frequencies for the different forces quoted. The objective to introduce the gravitational force or weight is the most quoted (21\%). The motivation to introduce the force acting on a body by contact is the second more frequent objective (14\%). Muscular force also has some relevance. The introduction of other forces such as friction and magnetic force and force related to rotatory motion also 
have some relevance. Finally, in several cases the role of everyday life emerged in evoking (36-11\%), making people live (8-2\%), explaining $(20-6 \%)$, making people understand (63-19\%) a force.

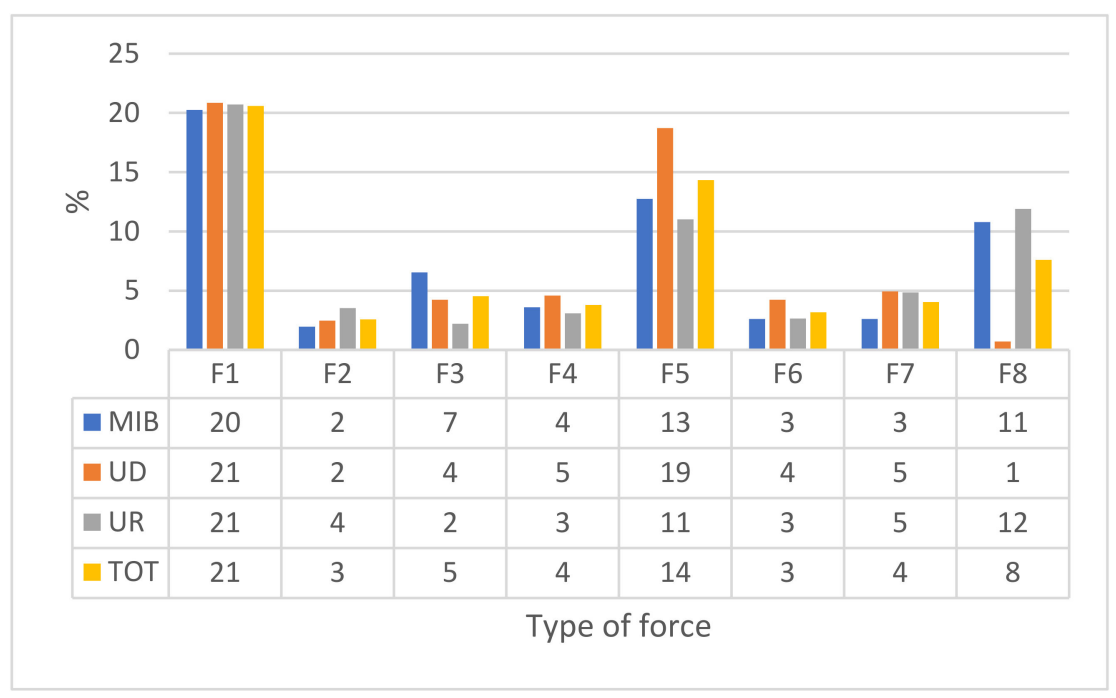

Figure 8. Disciplinary motivation related to the introduction, comprehension of a specific type of force (legend: F1 gravitational/weight force; F2 Elastic force; F3 Magnetic/electric/e.m. force; F4 friction force; F5 force acting on an object by contact; F6 centrifugal/centripetal force; F7 force of a system/wind force, etc.); F8 muscular/physical force.

\subsection{Didactic Motivation}

Regarding the results related to the justification of didactic effectiveness, as seen in Table 12 and Figure 9, the distribution is bimodal with the prevalence of categories C1.2 (experiences lived by the child) and C5 (justification related to comprehensibility). However, category C2 (Justification related to intention to act didactically) is well represented with insignificant differences.

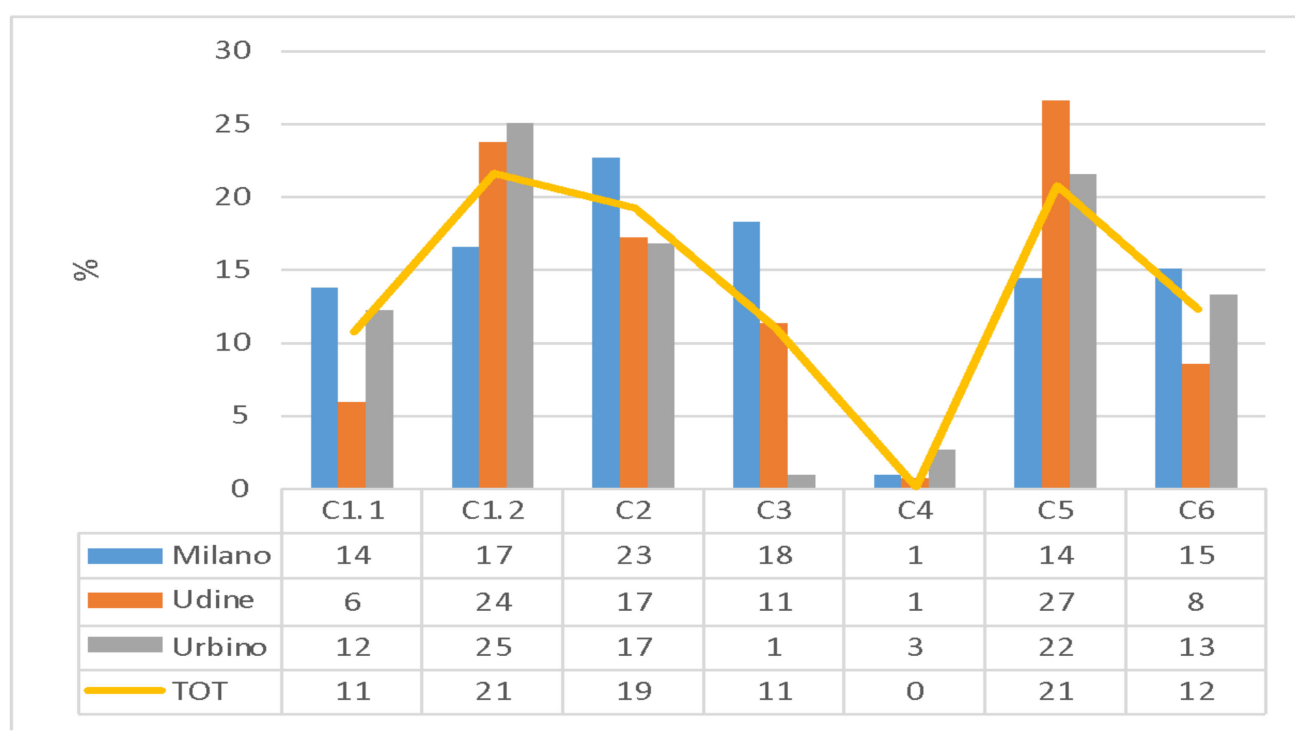

Figure 9. Distribution of the categories related to Didactic Motivation. 
Table 12. Frequencies of occurrences related to categories referred to Didactic motivation.

\begin{tabular}{ccccccccc}
\hline & C1.1 & C1.2 & C2 & C3 & C4 & C5 & C6 & TOT \\
\hline MIB & 42 & 51 & 69 & 56 & 3 & 44 & 46 & 311 \\
UD & 17 & 67 & 49 & 32 & 2 & 75 & 24 & 266 \\
UR & 28 & 57 & 38 & 2 & 6 & 49 & 30 & 210 \\
\hline TOT & 87 & 175 & 156 & 90 & 11 & 168 & 100 & 787 \\
\hline
\end{tabular}

The three distributions are quite similar to the distribution of the averages (continuous line). In other words, there do not appear to be significant differences from the mean (Figure 9).

More specifically, the highest frequency is found for category C1.2 "evocation of experiences lived and/or observed by the child". The student interprets a certain representation the more comprehensible the more familiar it is to the child. Another category widely reported by respondents was C5 "Justification related to comprehensibility," that is, a justification based on the clarity and intuitiveness of the proposed representation that does not require the support of other mediators to be understood.

The frequency of category C2 "justification linked to the intention to act didactically" is also high. We point out that this result may be influenced by the context of administration: the sample, as we already said, was in fact made up of students of Primary Education Sciences who tend to simulate the teaching activities related to their profession. However, category $\mathrm{C} 1$ is the one with the highest frequency, if we consider together categories C1.1 and $\mathrm{C} 1.2$, which both refer to the justification of the didactic effectiveness of the representation that we labeled "evocative", that is, based on the evocation of daily experiences of the child or of third persons.

The distribution of the responses of the three universities, as we said, is quite similar to the distribution of the averages. Looking at the absolute values, the most significant differences in the three universities are found, respectively, in the case of C5, much more frequent in the Udine sample, and in the case of C3, which is rarely present in the Urbino sample.

It is worth commenting on the low frequency relative to category $\mathrm{C} 4$, which we labeled as "Justification by formal proxy" (didactic contract). This finding needs to be explained since it seems inconsistent with what the educational literature states, recognizing students ${ }^{\prime}$ subjection to the clauses of the didactic contract. However, we believe that this depends on the survey mode adopted. The survey protocol detected the reasons for didactic effectiveness explicitly, thereby neglecting to detect the implicit reasons for the choices. However, the didactic contract is known to consist of implicitly assumed clauses of which the student is unaware. A limitation of the survey was not having interviewed the students who made those representations. Indeed, we could have possibly detected that some of their representations were suggested by their previous school experience, by what they had experienced in school or what they were used to reading in books. In summary, having identified an implicit category and having collected only explicit data justifies, in our opinion, the gap between the data detectable in the literature and the result of our research regarding the $\mathrm{C} 4$ category.

\section{Discussion}

\subsection{Discussion on Aspects of Disciplinary Didactics}

The same or similar situation or image is represented in connection with very different aspects, without, however, in most cases, clearly specifying which are the interacting systems or the system in exam, on which any forces act.

The contextualization, not accompanied by a rigorous identification of the interacting systems, of the types of interaction, introduces elements that can divert attention from the declared objective (the force of gravity), shifting the attention on the action the push, the hand that leaves the object. As is known from the literature, children indiscriminately 
attribute the cause of the object's fall to gravitational attraction (the efficient cause) or to the hand that left the object (the acting cause).

Situations involving forces exerted in contact between two bodies (push/pull) are prevalent. In particular, those in which a person exerts a force on an object are very frequent, which we know can give rise to the idea that forces are associated with living beings, which is quite present in the conceptions of the prospective teachers of our sample.

The representations in which the force of gravity comes into play are also quite numerous, and in most cases, they are distinct from those in which we speak of the force of weight (often identified as a property of systems). Force of gravity and force of weight are mostly distinguished, although there is an unspecified link between them.

For many prospective teachers, the need emerges to identify strength from effects as in the common sense of sensory information. This effect is mostly associated with moving or displacement or putting a system in motion. The number of prospective teachers who focus the representations on the concept of interaction and on the reciprocity of the forces of interaction is a minority. Some contexts seem to emerge as more familiar for grounding the concept of force as interaction, given that they are those in which the interacting nature of the concept of force has most often emerged: the tug-of-war; the Earth satellite or sun-earth interaction; the interaction between two people pushing each other.

Definitely a minority $(10 \%)$ is the presence of prospective teachers with a minimum basis on the concept of force and its formal-vector representation. Equally limited is the presence of prospective teachers with at least some awareness of the students' main learning problems, such as those related to strength and movement.

On the other hand, looking at the set of representations made by a student and the related motivations, we see that they underlie different didactic perspectives on the concept of force: force in situations of equilibrium; force to put a body in motion; force decline according to the different types of forces.

About a third of the representations concern static situations. Among them prevail those in which there are explicitly more forces acting on a body that balance each other. According to some didactic approaches (typically for basic school levels), it is possible to look at the concept of force as the entity that accounts for the equilibrium of systems. On the other hand, in two-thirds of the representations, there are situations of movement in which we can recognize two approaches to the concept of force, one that looks at force as the cause of movement (and which underlies the erroneous idea that a body can be in motion only if a force acts on them) and the other as a necessary cause for a stationary body to set in motion.

Finally, in the perspective of the different types of force, rather than introducing the concept of force as a vector, the purpose of the representations is to show that some forces act horizontally, others vertically, some attract others repel, one can shoot an object, but you can also push it. In other words, a unified concept of force is not created, but rather a collection of pictures in which it is the context that determines the significance of the example, rather than proposing them as examples to construct the different elements that contribute to forming a unitary concept of force. Even those $(63 \%)$ who motivate their representations by introducing a type of force (gravitational, rather than elastic, rather than friction, etc.) most often place themselves in this perspective, rather than in that of proposing a general concept of force inside a specific example.

\subsection{Discussion on Aspects of General Didactics}

Focusing now on the results related to the justification of the didactic effectiveness of the proposed representations, we can make the following concluding remarks.

Regarding the high frequency of category C1 (justification linked to the evocation of experiences), we can interpret this result in light of the influence of naive conceptions on child learning. Evocation of situations familiar to the child is considered a sufficient teaching condition to ensure understanding of the teaching content. In doing so, the respondents neglect the didactic transposition of knowledge and, therefore, do not consciously act on 
the selection of the elements of knowledge and on the most appropriate options of their didactic mediation. In contrast, this aspect is crucial in teacher education.

Students' naive conceptions also seem to play a relevant role in the results related to category C5 (justification related to comprehensibility). The representations proposed by the students are interpreted by them as self-evident and intuitive, in themselves sufficient to explain the content of the teaching. This result shows a lack of awareness of the didactic use of images which requires, instead, knowledge of the potential, constraints and limits of this particular type of didactic mediator.

Even the high frequency of responses obtained in category C2 (justification linked to the intention to act didactically), also considering the content of the individual descriptive responses, can be interpreted as revealing the persistence of naive conceptions regarding teaching. There is, indeed, an insistent reference to practical activities which, however, are not coherent and incisive with respect to the teaching content. The risk, therefore, is of a separation between the experiential moment and the moment of formal learning.

As far as qualitative aspects are concerned, we point out the influence of the administrative context. It should be remembered that the students attended different teaching courses: Image Education in Milan, Physics Education in Udine, Pedagogy of Knowledge in Urbino. Udine provided representations that were richer in detail than the responses obtained in the other universities. Although this issue requires further investigation, we may hypothesize that this still depends on the didactic contract: as attending a Physics course, students tend to satisfy the presumed expectation of the teacher to obtain representations as complete and precise as possible with respect to the teaching content.

A second qualitative aspect concerns the use of images to know. The research shows a general lack of awareness in the selection and use of images by students. This result suggests that we should question the relevance of this issue in teacher education.

A final consideration concerns the relationship between General Didactics and Disciplinary Didactics in teacher education. The construction of shared tools allows the integration of general didactic and disciplinary didactic perspectives related to two different professional dimensions of the teacher. Moreover, referring to operationalized categories, that is, expressed in terms of observable behaviors, enables us to look at the same educational phenomena from different perspectives. In the tool, the multi-perspective approach to the study of teaching situations is realized. Therefore, making teachers familiar with tools of this type in real teaching contexts allows them to increase their awareness of the multi-perspective nature of teaching work.

Author Contributions: Conceptualization, B.M., M.M., A.S. and M.T.; methodology, B.M., M.M., A.S. and M.T.; validation, B.M., M.M., A.S. and M.T.; investigation, B.M., M.M., A.S. and M.T.; data curation, A.S.; writing-original draft preparation, B.M., M.M., A.S. and M.T.; writing-review and editing, B.M., M.M., A.S. and M.T. All authors have read and agreed to the published version of the manuscript.

Funding: This research received no external funding.

Institutional Review Board Statement: Not applicable.

Informed Consent Statement: Informed consent was obtained from all subjects involved in the study.

Data Availability Statement: The data presented in this study are available on request from the corresponding author.

Conflicts of Interest: The authors declare no conflict of interest. 
Appendix A. The Form to Collect the Representations on Force Università degli Studi di Udine - Didattica della Fisica - Scienze della Formazione Primaria Marisa Michelini - Test - in Rappresentazioni - 25/9/19

COGNOME E NOME

Matricola

RAPPRESENTAZIONI CHE FAVORISCONO LA COMPRENSIONE DEL CONCETTODI FORZA Che rappresentazione faresti per aiutare la comprensione del concetto di forza?

Fai 3 rappresentazioni. Descrivi ciascuna di esse. Illustra per ciascuna di esse perché la ritieni

efficace sul piano didattico e sul piano disciplinare

\begin{tabular}{|l|l|}
\hline Rappresentazione l & Descrizione della rappresentazione \\
& \\
\hline $\begin{array}{l}\text { perché ritieni efficace questa rappresentazione sul } \\
\text { piano didattico }\end{array}$ & $\begin{array}{l}\text { perché ritieni efficace questa } \\
\text { rappresentazione sul piano disciplinare }\end{array}$ \\
\hline $\begin{array}{l}\text { Rappresentazione 2 } \\
\text { piano didattico }\end{array}$ & \\
\hline & \\
& \\
& \\
& \\
\hline
\end{tabular}

\begin{tabular}{|l|l|}
\hline Rappresentazione 3 & \\
& \\
& \\
\hline $\begin{array}{l}\text { perché ritieni efficace questa rappresentazione sul della rappresentazione } \\
\text { piano didattico }\end{array}$ & $\begin{array}{l}\text { perché ritieni efficace questa } \\
\text { rappresentazione sul piano disciplinare }\end{array}$ \\
\hline
\end{tabular}

OSSERVAZIONI e Commenti 


\section{Appendix B}

Table A1. Concept of force in Physics: Founding nuclei and Conceptual Aspects.

\begin{tabular}{ll}
\hline Founding Nucleus & Conceptual Aspects \\
\hline $\begin{array}{l}\text { Force is the formal } \\
\text { descriptor of the interaction }\end{array}$ & $\begin{array}{l}\text { Need for two interacting systems (not just one system) } \\
\text { Pairs of forces, each acting on one of the two interacting systems } \\
\text { (not a single force acting on a single system) }\end{array}$ \\
\hline Effects of a force on a system & $\begin{array}{l}\text { System identification } \\
\text { Effect: Deformation-see cases of elasticity } \\
\text { Effect: Acceleration-see the three laws of dynamics }\end{array}$ \\
\hline $\begin{array}{l}\text { Center of mass } \\
\text { Formalization 1: vectorial } \\
\text { nature }\end{array}$ & $\begin{array}{l}\text { Representation with an applied vector (originates in a } \\
\text { sell-defined physical point) }\end{array}$ \\
\hline $\begin{array}{l}\text { Measure of a force in static } \\
\text { conditions }\end{array}$ & $\begin{array}{l}\text { Dinamometer of the point to which to aptic deformation defines the force indicator } \\
\text { (operational force def) [dynamic force measurement: no] }\end{array}$ \\
\hline $\begin{array}{l}\text { Formalization 2: } \\
\text { composition }\end{array}$ & Vectorial sum (parallelogram rule) \\
\hline
\end{tabular}

1. Inertial systems and dynamic equilibrium (uniform motion of the system, that is $v=$ cost). Identification of the inertial reference system!

2. Model of material point to which to apply the force and identification of the two interacting systems for each assigned force

- $\quad$ identification of the mass $m$ (tot) in motion and of the point that represents it

- identification of the net force in an inertial system

The three principles of

- acceleration as an effect on $\mathrm{m}$ (tot) dynamics:

1. principle of inertia

2. $\mathrm{F}=\mathrm{ma}$

3. Action reaction

\section{cases:}

$\bigcirc \quad$ equilibrium case of forces in the inertial system (attention -> no inertial "forces", such as centrifuge)

- central forces case and centripetal acceleration in uniform circular motion

not uniform motion case and decomposition of the effects in centripetal and tangential acceleration

0 if $\mathrm{F}$ increases a increases too ( $\mathrm{m}$ being equal); $0 \quad$ with the same F, the acceleration depends on the mass of the system according to the inverse ratio of the masses

3. Equal and opposite forces applied to different systems

Force measure in dynamical Inertial mass

conditions Inertial balance

Impulse $(\mathrm{F} \Delta \mathrm{t})$ and variation of momentum $(\Delta \mathrm{p}): \mathrm{F} \Delta \mathrm{t}=\Delta \mathrm{p}$

Formalization 3: application

$\mathrm{F}$ to a system and $\Delta \mathrm{p}$

(change in quantity of

motion): Impulse and

change in momentum
- Monodimensional case (for the decomposition principle)

Conservation of momentum $\mathrm{p}=\mathrm{mv}$

Concepts to reanalyze

- $\quad$ If $\mathrm{F} / /$ vo $\rightarrow$ the module of $\mathrm{v}$ change $\left(\mathrm{vo} \rightarrow \mathrm{v}^{\prime}\right)$

- $\quad$ If $\mathrm{F} \perp$ vo $\rightarrow$ direction changes 
Table A1. Cont.

\begin{tabular}{|c|c|}
\hline Founding Nucleus & Conceptual Aspects \\
\hline $\begin{array}{l}\text { Types of force: } \\
\text { - } \quad \text { Weight } \\
\text { - } \quad \text { Elastic } \\
\text { - } \quad \text { Gravitational } \\
\text { - } \quad \text { Friction: sliding, } \\
\text { - } \quad \text { Elvent, Viscous } \\
\text { - } \quad \text { Magnetic } \\
\text { - } \quad \text { Nuclear }\end{array}$ & $\begin{array}{l}\text { Which are indicated and in which contexts } \\
\text { (what do they put ?: drawing, graph, formula) } \\
\text { Formal expressions } \\
\text { - } \quad \mathrm{F}=\text { cost e } \mathrm{F}=\mathrm{mg} ; \\
\text { - } \mathrm{F}=-\mathrm{kx} ; \\
\text { - } \quad \mathrm{F}=\text { several relations } \\
\text { - } \quad \mathrm{F}=\mathrm{GM} 1 \mathrm{M} 2 / \mathrm{r}^{2} \\
\text { - } \quad \mathrm{F}=-\mathrm{kv} \ldots\end{array}$ \\
\hline $\begin{array}{l}\text { Types of forces organization: } \\
-\quad \text { Linear and central } \\
-\quad \text { Active and passive } \\
-\quad \text { Volume/Surface force }\end{array}$ & $\begin{array}{l}\text { Which are indicated and in which contexts } \\
\text { Origin of friction } \\
\text { Origin of normal force to the constraint }\end{array}$ \\
\hline $\begin{array}{l}\text { Equilibrium of a body or } \\
\text { particles system under static } \\
\text { conditions: }\end{array}$ & $\begin{array}{l}\text { Equilibrium of the material point. } \\
\text { Equilibrium of forces acting on the same system }(\mathrm{v}=0 \text { case }) \\
\text { Dynamical equilibrium of forces acting on the same system }(\mathrm{v}= \\
\text { vo constant case) }\end{array}$ \\
\hline $\begin{array}{l}\text { Equilibrium in static } \\
\text { conditions: moment of } \\
\text { forces and rigid body }\end{array}$ & $\begin{array}{l}\text { Equilibrated moments (and Forces) acting on the same system } \\
\text { Applicazions } \\
\text { - } \quad \text { Balance } \\
\text { - } \quad \text { Levers }\end{array}$ \\
\hline $\begin{array}{l}\text { Action of a moment of forces } \\
\text { and rigid body }\end{array}$ & $\begin{array}{l}\text { Balanced moments (and forces) acting on the same system (no } \\
\text { rotations: } \omega=0 \text { ) } \\
\text { Unbalanced forces acting on the same system (the system rotates: } \\
\omega \neq 0 \text { ) and we look at the conservation of the angular } \\
\text { momentum (see dancer, diver, etc.) }\end{array}$ \\
\hline
\end{tabular}

\section{Appendix C}

Table A2. Summary of scientific concepts and common sense ideas related to these concepts that emerged from the literature on learning processes [31,32].

\begin{tabular}{|c|c|c|}
\hline \multicolumn{2}{|c|}{ Common Sense Conception } & References \\
\hline \multicolumn{3}{|c|}{ Nature of the Concept of Force } \\
\hline \multirow{3}{*}{\multicolumn{2}{|c|}{$\begin{array}{l}\text { A1-Force Identified with the action of a system on another at a contact (not at a distance) } \\
\text { A1.1 Force identified with the action of a system on another at a contact [non reaction] } \\
\text { A2. Force as property of a system (force of the wind, force of a person, force of a } \\
\text { projectile, weight of a body) }\end{array}$}} & [33-36] \\
\hline & & {$[33,37-41]$} \\
\hline & & {$[33,35,42]$} \\
\hline \multirow{2}{*}{\multicolumn{2}{|c|}{$\begin{array}{l}\text { A2.1. Force associated to living beings or some machinery } \\
\text { A3. A force produces movement or other changes (explosion, collision) }\end{array}$}} & {$[33,34,43-45]$} \\
\hline & & {$[33-35,43,46-50]$} \\
\hline \multicolumn{3}{|c|}{ Indicators of the existence of a force-effect produced by a force } \\
\hline \multirow[t]{2}{*}{ Acceleration deformazione } & B1-Displacement, moviment, velocity & {$[33-35,43,46-52]$} \\
\hline & $\begin{array}{l}\text { B2. Weight of an object [indicator of the force } \\
\text { needed for displace it] }\end{array}$ & {$[43,53-57]$} \\
\hline \multicolumn{3}{|c|}{ Types of force } \\
\hline Weight force & $\begin{array}{l}\text { C1.1 Weight as property of a body } \\
\text { C1.2 On the way up, the push of the hand acts on } \\
\text { the descent of the weight } \\
\text { C1.3. Weight distinct from gravitational force }\end{array}$ & {$[35,53-55]$} \\
\hline Magnetic force & $\begin{array}{l}\text { C2.1. Magnetic force acting only on a } \\
\text { ferromagnetic object (not on the magnet) }\end{array}$ & [41] \\
\hline Dipole moment as source & C2.2 Magnetic force as effect of charge & [41] \\
\hline Elastic force & C3. Force of a spring & [54-58] \\
\hline
\end{tabular}




\section{References}

1. Duit, R.; Gropengießer, H.; Kattmann, U.; Komorek, M.; Parchmann, I. The Model of Educational Reconstruction-A Framework for Improving Teaching and Learning Science. In Science Education Research and Practice in Europe. Cultural Perspectives in Science Education; Jorde, D., Dillon, J., Eds.; Sense Publishers: Rotterdam, The Netherlands, 2012; Volume 5. [CrossRef]

2. Halliday, M.A.K. Language as Social Semiotic. The Social Interpretation of Language and Meaning; Edward Arnold Publishers: London, UK, 1978.

3. Bailey, J.M.; Slater, T.F. A review of astronomy education research. Astron. Educ. Rev. 2004, 2, 20-45. [CrossRef]

4. Ojala, J. The third planet. Int. J. Sci. Educ. 1992, 14, 191-200. [CrossRef]

5. Kikas, E. Pupils' explanations of seasonal changes: Age differences and the influence of teaching. Br. J. Ed. Psych. 1998, 68, 505-516. [CrossRef]

6. Mishra, P. The role of abstraction in scientific illustration: Implications for pedagogy. J. Vis. Lit. 1999, 19, 139-158. [CrossRef]

7. Pena, B.M.; Quilez, M.J.G. The importance of images in astronomy education. Int. J. Sci. Educ. 2001, 23, 1125-1135. [CrossRef]

8. Vosniadou, S. Instructional considerations in the use of external representations: The distinction between perceptually based depictions, and pictures that represent conceptual models. In Use of Representations in Reasoning and Problem Solving; Verschaffel, L., de Corte, E., de Jong, T., Elen, J., Eds.; Routledge: New York, NY, USA; Abingdon, VA, USA, 2010; pp. 36-54. [CrossRef]

9. Kress, G.; van Leeuwen, T. Reading Images: The Grammar of Visual Design; Routledge: London, UK; New York, NY, USA, 1996.

10. Damiano, E. Il Dilemma del Centauro. Stato dell'arte della Ricerca su Didattica Generale e Didattiche Disciplinari; Vita e Pensiero: Milano, Italy, 1996.

11. Damiano, E. Il Sapere Dell'insegnare; Angeli: Milano, Italy, 2007.

12. Martini, B. Didattica e didattiche: La dialettica generale/specifico nell'articolazione del campo della didattica. Pedagog. Più Didatt. 2014, 1, 79-87.

13. Chevallard, Y. Concepts fondamentaux de la didactique: Perspectives apportées par une approche anthropologique. Rech. Didact. Mathématiques 1992, 12, 73-112.

14. Ligozat, F.; Coquidé, M.; Marlot, C.; Verscheure, I.; Sensevy, G. Didactiques et/ou didactique. Poursuivre le travail de problématisation. Éducation Didact. 2014, 8, 101-116. [CrossRef]

15. Martinand, J.-L. Point de vue V. Didactique des sciences et Techniques, didactique du curriculum. Éducation Didact. 2014, 8, 65-76. [CrossRef]

16. Reuter, Y. Didactiques et disciplines: Une relation structurelle. Éducation Didact. 2014, 8, 53-64. [CrossRef]

17. Vollmer, H.J. Didactique disciplinaire en Allemagne: Développement et perspectives. In Didactique en Construction. Constructions des Didactiques; Dorier, J.-L., Leutenegger, F., Schneuwly, B., Eds.; De Boeck: Bruxelles, Belgium, 2013 ; pp. $39-62$.

18. Chevallard, Y. La Transposition Didactique. Du Savoir Savant au Savoir Enseigné; La Pensée Sauvage: Grenoble, France, 1991.

19. Brousseau, G. Théorie des Situations Didactiques; La Pensée Sauvage: Grenoble, France, 1998.

20. Anning, A. Teachers' theories about children's learning. In Teachers' Professional Learning; Calderhead, J., Ed.; Farmer Press: London, UK, 1988; pp. 128-144.

21. Antonietti, A. Apprendimento: Che cosa se ne pensa oggi. Scuola Italiana Moderna 1998, 105, 11-13.

22. Calderhead, J. Teachers: Beliefs and knowledge. In Handbook of Educational Psychology; Berliner, D.C., Calfee, R.C., Eds.; MacMillan: New York, NY, USA, 1996; pp. 88-101.

23. Putnam, R.T.; Borko, H. Teacher learning: Implications of new views of cognition. In International Handbook of Teachers and Teaching; Biddle, B.J., Good, T.L., Goodson, I.F., Eds.; Kluwer: Dordrecht, The Nederland, 1997; pp. 21-36. [CrossRef]

24. Antonietti, A.; Liverta Sempio, O.; Marchetti, A.; Pérez-Tello, S. Che cos'è l'apprendimento? Le Concezioni Degli Studenti; Carocci: Roma, Italy, 2005.

25. Damiano, E. La Mediazione Didattica; Franco Angeli: Milano, Italy, 2016.

26. Landriscina, F. Modelli di riferimento per l'uso didattico della comunicazione visiva. In Principi di Comunicazione Visiva e Multimediale. Fare Didattica con le Immagini; Calvani, A., Ed.; Carocci: Roma, Italy, 2011; pp. 43-74.

27. Calvani, A. Principi di Comunicazione Visiva e Multimediale. Fare Didattica con le Immagini; Carocci: Roma, Italy, 2011.

28. Fischbein, E. The Theory of Figural Concepts. Educ. Stud. Math. 1993, 24, 139-162. [CrossRef]

29. Shulman, S. Those Who Understand. Educ. Res. 1986, 15, 4-14. [CrossRef]

30. Shulman, L.S. Knowledge and teaching: Foundations of the new reform. Harv. Educ. Rev. 1987, 57, 1-22. [CrossRef]

31. Duit, R. Bibliography—STCS. 2009. Available online: https://archiv.ipn.uni-kiel.de/stcse/ (accessed on 31 August 2021).

32. Demirci, N. A study about students' misconceptions in force and motion concepts by incorporating a web-assisted physics program. Turk. Online J. Educ. Technol. TOJET 2005, 4, 40-48.

33. Halloun, I.A.; Hestenes, D. Common sense concepts about motion. Am. J. Phys. 1985, 53, 1056-1065. [CrossRef]

34. Minstrell, J. Facets of Students' Thinking. In Research in Physics Learning: Theoretical Issues and Empirical Studies; Duit, R., Goldberg, F., Niedderer, H., Eds.; IPN Kiel: Kiel, Germany, 1992; pp. 110-128. Available online: https://www.researchgate.net/profile/ Hans-Niedderer/publication/330993365_Research_in_Physics_Learning_Theoretical_Issues_and_Empirical_Studies/links / 5c5f8abea6fdccb608b40ca2/Research-in-Physics-Learning-Theoretical-Issues-and-Empirical-Studies.pdf\#page=110 (accessed on 31 August 2021).

35. Ioannides, C.; Vosniadou, S. The changing meanings of force: From coherence to fragmentation. Cogn. Sci. Q. 2002, 2, 5-62.

36. Watts, M. A study of schoolchildren's alternative frameworks of the concept of force. Eur. J. Sci. Educ. 1983, 5, 217-230. [CrossRef] 
37. Brown, D.E. Students' concept of force: The importance of understanding Newton's third law. Phys. Educ. 1989, $24,353-358$. [CrossRef]

38. Thornton, R.K.; Sokoloff, D.R. Assessing student learning of Newton's laws: The Force and Motion Conceptual Evaluation and the Evaluation of Active Learning Laboratory and Lecture Curricula. Am. J. Phys. 1998, 66, 338-352. [CrossRef]

39. Bao, L.; Hogg, K.; Zollman, D. Model analysis of fine student models: An example with Newton's third law. Am. J. Phys. 2002, 70, 766-778. [CrossRef]

40. Kücüközer, A. Evolution of the students' conceptual understanding in the case of a teaching sequence in mechanics: Concept of interaction. Eurasia J. Math. Sci. Technol. Educ. 2006, 2, 30-40. [CrossRef]

41. Galili, I. Mechanics background influences students' conceptions in electromagnetism. Int. J. Sci. Educ. 1995, 17, 371-387. [CrossRef]

42. Reiner, M.; Slotta, J.D.; Chi, M.T.H.; Resnick, L.B. Naïve physics reasoning: A commitment to substance based conceptions. Cogn. Instr. 2000, 18, 1-34. [CrossRef]

43. Gilbert, J.; Watts, M. Misconceptions and alternative conceptions: Changing perspectives in science education. Stud. Sci. Educ. 1983, 10, 61-98. [CrossRef]

44. Kolokotronis, D.; Solomonidou, C. Students' conceptions about mechanical interaction and design of appropriate educational software for constructive teaching. In Science Education Research, in the knowledge Education Society; Psillos, D., Kariotoglou, P., Tselfes, V., Eds.; Aristothelean University: Thessaloniki, Greece, 2001; pp. 480-482.

45. Tytler, R.; Darby, L.; Peterson, S. Movement and force. In Teaching Primary Science Constructively; Skamp, K., Ed.; Cengage: Melbourne, Australia, 2012; pp. 99-142.

46. Viennot, L. Spontaneous reasoning in elementary dynamics. Eur. J. Sci. Educ. 1979, 1, 205-225. [CrossRef]

47. Clement, J. Students' preconceptions in introductory mechanics. Am. J. Phys. 1982, 50, 66-71. [CrossRef]

48. Osborne, R.; Freyberg, P. Learning in Science: The Implications of Children' Scienc; Heineman: London, UK, 1985.

49. Chee, C.T. Misconceptions concerning laws of motion, frictional force and work done among gifted, above-average and average achieving students at upper secondary level. In Proceedings of the Workshop on Research for Students' Conceptual Structures and Changes in Learning Physics; Pak, S., Ed.; National University: Seoul, Korea, 1988; pp. 165-190.

50. Chee, C.T. Common Misconceptions in Frictional Force among University Physics Students. Teach. Learn. 1996, 16, 107-116.

51. Bryce, T.; Mac Millan, K. Encouraging conceptual change: The use of bridging analogies in the teaching of action-reaction forces and the 'at rest' condition in physics. Int. J. Sci. Educ. 2005, 27, 737-763. [CrossRef]

52. Low, D.; Wilson, K. Weight, the Normal force and Newton's Third Law: Dislodging a deeply embedded misconception. J. Aust. Sci. Teach. Assoc. 2017, 63, 17-26.

53. DiSessa, A. Phenomenology and the evolution of intuition. In Mental Models; Gentner, D., Stevens, A.L., Eds.; Erlbaum: Hillsdale, NJ, USA, 1983; pp. 15-33.

54. Trumper, R. A longitudinal study of physics students' conceptions of force in pre-service training for high school teachers. In Research in Science Education-Past, Present, and Future; Komorek, M., Behrendt, H., Dahncke, H., Duit, R., Graeber, W., Kross, A., Eds.; IPN Kiel: Kiel, Germany, 1999; Volume 1, pp. 253-255.

55. Trumper, R.; Gorsky, P. A cross-college age study about physics students' conceptions of force in pre-service training for high school teachers. Phys. Educ. 1996, 31, 227-235. [CrossRef]

56. Bliss, J.; Ogborn, J. Force and motion from the beginning. Learn. Instr. 1994, 4, 7-25. [CrossRef]

57. DiSessa, A. How should we go about attributing knowledge to students? In Research on Physics Education; Redish, E.F., Vicentini, M., Eds.; Società Italiana di Fisica: Bologna, Italy, 2004; pp. 117-135.

58. Hestenes, D.; Wells, M.; Swackhamer, G. Force concept inventory. Phys. Teach. 1992, 30, 141-166. [CrossRef] 